\title{
Application of Evolutionary Optimization in Structural Engineering
}

\author{
Hitoshi Furuta ${ }^{1}$, Koichiro Nakatsu ${ }^{2}$, Takahiro Kameda ${ }^{1}$, \\ and Dan M. Frangopol ${ }^{4}$ \\ 1 Department of Informatics, Kansai University, Takatsuki, Osaka 569-1095, Japan \\ furuta@res.kutc.kansai-u.ac.jp, \\ kamechan@sc.kutc.kansai-u.ac.jp \\ 2 Graduate School of Informatics, Kansai University, Takatsuki, Osaka 569-1095, Japan \\ inside2asc.kutc.kansai-u.ac.jp \\ 3 Department of Civil and Environmental Engineering, Lehigh University, Bethlehem, \\ PA 18015-4729, USA \\ dan.frangopol@lehigh.edu
}

\begin{abstract}
Practical optimization methods including genetic algorithms are introduced, based on evolutionary computing or soft computing. Several application examples are presented to demonstrate and discuss the efficiency and applicability of the described methods.
\end{abstract}

\section{Introduction}

Due to the recent advance and development of computer and information technologies, it becomes possible to obtain useful information for decision making with ease. To resolve some problems facing in real life, it is necessary to find out an appropriate solution among possible candidates under several constrained conditions. Therefore, most of these problems are belonging to a kind of optimization problems. However, most of optimization problems being studied are solved under ideal circumstances. Most of real life problems are very large and complicated ones with vague or uncertain objective functions and constrained conditions, different from the ideal circumstances.

Under such circumstances, evolutionary computing has been paid great attention and recognized as a powerful tool for optimization of various practical problems. Evolutionary computing uses iterative procedures, such as growth or development in a population. This population is then selected in a guided random search using parallel processing to achieve the desired end. Such processes are often inspired by biological mechanisms of evolution. Evolutionary computing includes evolutionary programming, genetic algorithm, genetic programming, immune algorithm, learning classifier system, particle swarm optimization, ant colony optimization, etc. Among them, genetic algorithm has been widely used in various fields, because it is a representative method of the evolutionary computing and has a good ability to find out quasi-optimum solutions with ease.

In this paper, several practical optimization methods including GA are introduced, which are based on "evolutionary computing" or "soft computing". Soft computing covers fuzzy decision making, neural networks, and so forth. Several application examples 
are presented to demonstrate and discuss the efficiency and applicability of the methods described here.

\section{Structural Vibration Control Using Soft Computing Techniques}

In Japan, many high-rise structures have been constructed due to the recent advance of structural material and construction technology. Since the high-rise structures are generally very flexible, vibration control is essential to maintain safety and reliability of the structures. Especially, natural disasters which cause the strong vibration, like typhoon and earthquake should be considered in their design and construction.

Under such situations, a lot of researches on the vibration control have been done in the past [1], most of which do not consider the structural and environmental changes in time. Those systems may lose the performance when the environment has a perceptible change. In actual cases, the characteristics of structures may change due to the structural degradation and the addition of other facilities to the structure. This implies that it is necessary to deal with the structural and environmental changes when designing the vibration control system. There are some robust and adaptive systems that can consider the change of environment. However, in those systems, the structural performance in the static environment may be reduced. In the case, it is essential to adapt to the changing environment quickly while maintaining the performance in the static environment.

In this paper, a new structural vibration control system is described, which can adapt to the change of structural systems and environments, by introducing the learning ability. In this system, it is necessary to prevent the reduction of the performance in the static state, while improving the effectiveness of adaptation and the performance after learning. This system has two different controllers: a robust controller used for the static state and an adaptive controller following the change of environment. By using these two controllers properly, it is possible to achieve a good control performance under any situation. Fuzzy controller is employed for the adaptive controller that can adapt to the change of structural systems, in which the steepest descent method is employed for the learning method. In addition to the two controllers, the system has a judgment ability to recognize the change of environment based on structural response, external force, and control power. Through numerical and model experiments, it is concluded that the system can provide a good control for the unforeseen and incidental changes of external loads and conditions.

\subsection{Vibration Control System}

The present system has two controllers and one judgment machine. While both controllers calculate control force from structural response and external force all the time, the system uses one of the outputs provided by the two controllers. The structure of the system is shown in Fig.11.

\subsubsection{Robust Controller}

In the robust controller, the control force is calculated by fuzzy-neural network system $[2,3]$. Although fuzzy-neural network is one of neural networks [4], it can provide the 


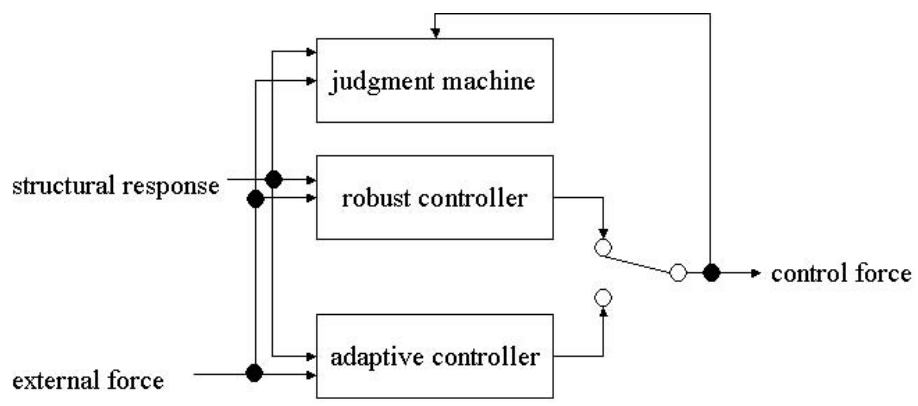

Fig. 1. Structure of the system

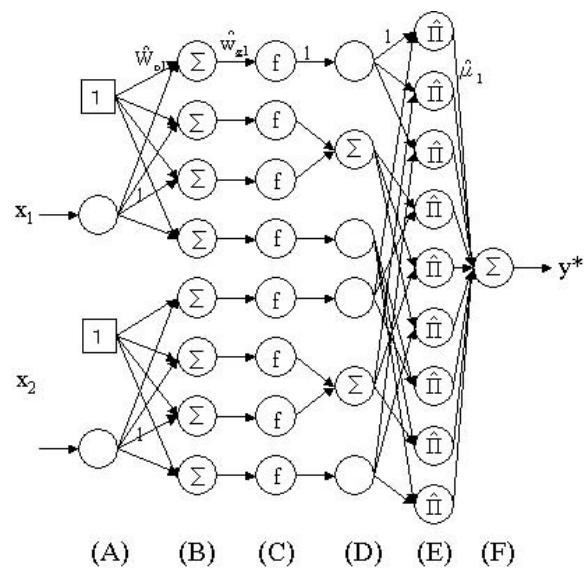

Fig. 2. Structure of fuzzy-neural network

calculating results equal to the fuzzy reasoning method. Therefore, it has characteristics of both neural network and fuzzy reasoning, namely, learning ability of neural network and robustness of fuzzy reasoning. The structure of fuzzy-neural network system is shown in Fig. 2

This system uses the simplified fuzzy reasoning in which the consequent part is expressed in terms of crisp numbers. In Fig. 2, layers A to D correspond to antecedent parts, and layers E to F correspond to consequent parts. Membership functions are expressed by sigmoid function, and their central values are depicted by the weights between A and B and gradients are depicted by the weights between B and C. Consequent parts are weighted from $\mathrm{E}$ to $\mathrm{F}$. Using the sigmoid function, it is possible to define the shape of membership functions in anti-symmetrical forms. Thus, it is possible to realize a better fitting and a better control than with symmetrical membership functions. Those three kinds of weights are learned using the back propagation algorithm.

The robust controller has a learning ability, which is not performed under control, and can avoid over-learning and over-reaction to the change of state. In the system, the 
neural network has already learned good control patterns by the optimal control theory with the same structure. This means that the neural network may be able to have a control performance equivalent to the optimal control theory. The fuzzy-neural network used here can calculate faster and has robustness, because its structure includes the fuzzy reasoning process. In other words, it can calculate the control force providing good performance equivalent to the optimal control theory in shorter time, and the deterioration of performance at the change of environment is smaller than with the optimal control theory.

\subsubsection{Adaptive Controller}

For the adaptive controller, the control force is calculated by fuzzy control with a learning mechanism using the steepest decent method. Since the learning method is the same as for the neural network, this fuzzy control system is called neuro-fuzzy system. The neuro-fuzzy system has also the characteristics of both neural network and fuzzy reasoning that are the learning ability of the neural network and the robustness of the fuzzy reasoning. However, neuro-fuzzy structure is simpler than fuzzy-neural network, and therefore the learning is faster and convergence is generally quick. This implies that neuro-fuzzy system is well suited to adaptive controller. In the present system, Gauss function is employed for the membership function. The neuro-fuzzy system can tune the membership functions whose consequent parts are tuned with the steepest decent method by fitting the teaching data. Then, it is necessary to prepare teaching data to learn, however it is impossible to collect the complete teaching data, because the state is so quickly changing that the optimal solution cannot be identified. In other words, if the state of structure is changing, it is not able to know the exact vibration characteristics under the control. In this research, structure response after control is given to the neuro-fuzzy system, in which the system learns the teaching data that are created when the structural response velocity is smaller than that under the previous control. Namely, the teaching data are supposed to be a vector with the inverse direction of structural response. The learning is done at each step. In this way, good rules of reducing the vibration of structure are obtained. Moreover, the calculation is implemented in a faster manner, and the controller has robustness, because the calculation method is based on fuzzy reasoning.

\subsubsection{Judgment Machine}

Judgment machine is always checking the performance of robust controller to find out the reduction of the performance based on the structural response, external force, and control power. When the vibration characteristics change, some difference appears on those three data. If the structural response differs even for the same external force and the same control power is outputted, judgment machine can recognize some change of environment.

\subsubsection{Model Experiment}

To validate the performance of each controller, model experiment using rigid frame model is conducted. In the experiment, the structure and environment are not changed. As external force, actual earthquake data observed at Kobe in 1995 are used. The results 


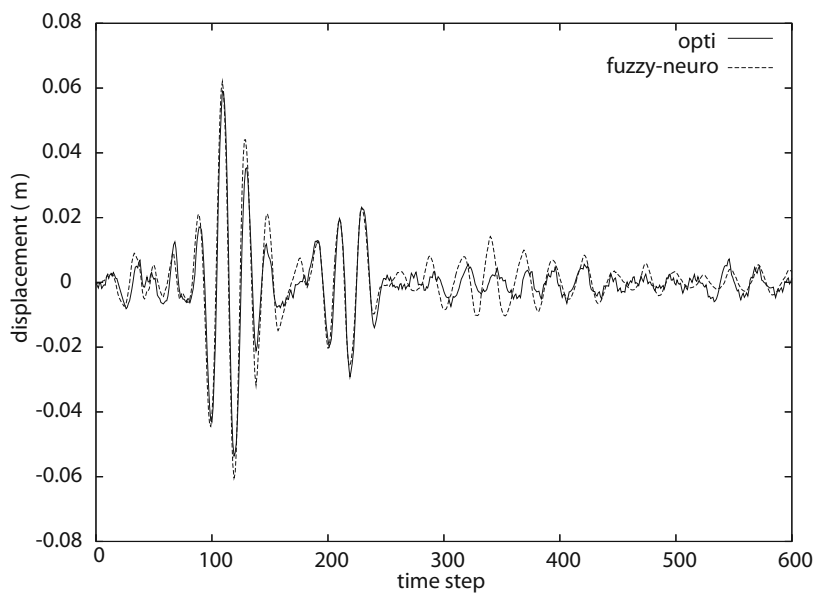

Fig. 3. Experiment result of robust controller

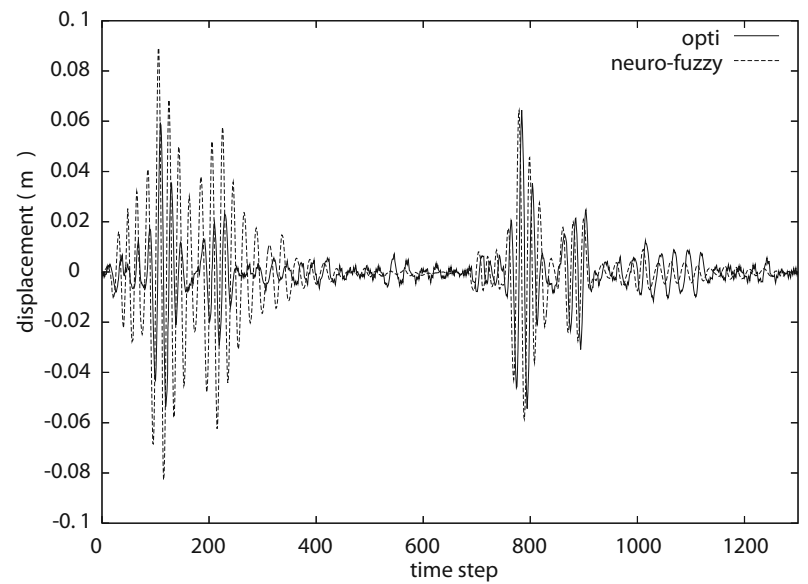

Fig. 4. Experiment result of adaptive controller

of both controllers are shown in Figs. 3 and 4 together with the results of optimal control theory. The robust controller has seven membership functions, which are allocated at even intervals at first. The robust controller has already learned a part of results given by the optimal control theory. However, the input patterns to the system are unknown at the experiment. From Fig. 3, it can be confirmed that the robust controller has as good performance as that by the optimal control theory. In other words, the robust controller can obtain good control rules that are equally efficient as those of the optimal control theory. On the other hand, the adaptive controller has no information regarding the structure and environment at first. The controller has also seven membership functions, in which all consequent parts are initialized to be zero. At the initial stage, the adaptive 
controller cannot control well and there are big differences from that of the optimal control theory, because it has no information about the environment. However, the performance of control is gradually improved step by step as the learning proceeds. Finally, the performance of adaptive controller becomes equal to the optimal control theory, as shown in Fig. 4. From this result, it is confirmed that this controller can adapt quickly and rightly even though it has no knowledge about the structure and environment. This means that the present system can adapt to the changing environment, therefore it is useful for the control under the dynamic environment.

\subsubsection{Numerical Example}

To demonstrate the effectiveness of the present system, numerical experiment is done. In this experiment, the frequency characteristic of the structure is changed. The weight of the structure is increased from time to time. In the experiment, the external force is calculated from the actual wind velocity of the 9th typhoon in Osaka on July 26, 1997. This data are observed at the interval of 0.05 second and the total number of data is 30,000. The numerical results by the present system are shown in Fig. 5 comparing with the results by the optimal control theory. In the experiment, the structural weight becomes double after 500 steps. At first, both the systems show almost the same performance at the static state. When the structural characteristics begin to change, some difference appears. While the difference is small at first, the performance of the present system provides better results than the optimal control theory, because of the robustness of the present system. As time proceeds, the difference of performance becomes larger gradually. This shows that the proposed system can adapt to the change of structural characteristic. Since the present system could identify the change of structure and environment, it switched the controller from the robust one to the adaptive one efficiently. The adaptive controller could adapt to the new environment quickly.

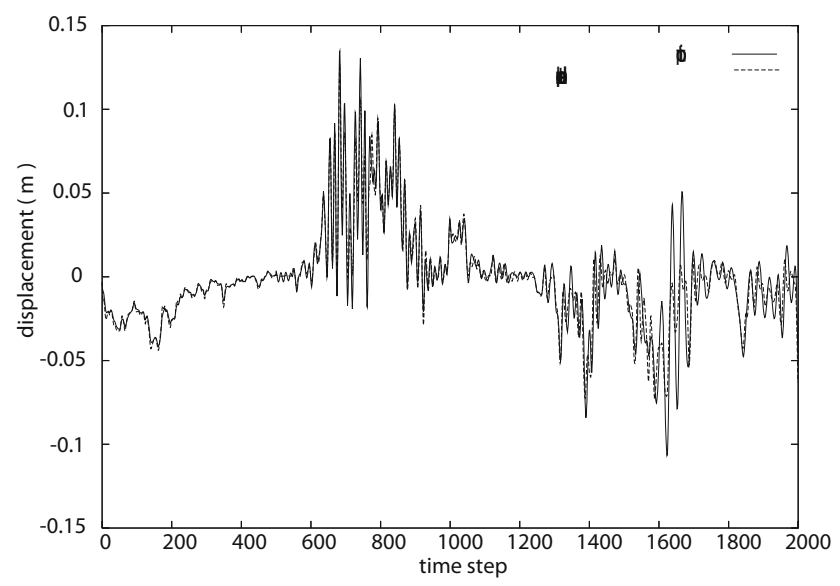

Fig. 5. The numerical results by the present system 


\section{Aesthetic Design of Bridge Structures}

In recent years it is becoming important to consider the aesthetic design factors in the design of bridges. Various researches (e.g. [6]) on the decision-support systems for aesthetic design of a bridge have been made in the past. Here, a practical decision support system for aesthetic design of bridge handrails is introduced. In the design of a bridge handrail, outsourcing the design works to a specialized designer to ensure an aesthetically satisfactory design can cause not only budgetary problems, but also a gap between what the designer imagines and what the engineers think on the structural design.

This paper takes the view that it is possible to obtain new designs by combining components for handrails which were designed in the past, because it would not be easy to create an original new design. Moreover, such use of handrail components designed in the past will be considered to allow candidate aesthetic designs smoothly because there will be no structural problems with components designed in the past.

In this paper, several attempts are presented to develop a decision support system for aesthetic design of bridge handrails. The decision support system consists of the evaluation system using neural network and the optimization system based upon immune algorithm. Thus, it is confirmed that the present system is effective for the aesthetic design of bridge handrails by means of several numerical examples. Furthermore, some of the results obtained are visualized through the use of computer graphics (CGs) and compared.

\subsection{Immune Algorithm and Neural Network}

Immune algorithms [7] are a kind of optimal solution search algorithms allowing the diversity of solutions to be retained and multiple quasi-optimal solutions to be obtained. It is considered that immune algorithms are suitable for practical aesthetic designing because of these characteristics, which allow two or more different quasi-optimal solutions rather than a single optimal solution to be obtained to a problem which is difficult to evaluate in a standardized manner, such as an aesthetic design. Consequently, an engineer can select an appropriate candidate from them based on his subjective judgment and preferences.

A neural network is a computer simulation of a neuron network. It is considered that characteristics of a neuron network can be utilized to make evaluations of bridge handrails designed by experts to acquire the touch of an expert. Therefore, a near-expert level evaluation can be provided through the use of a neural network without an expert, if once the necessary knowledge is acquired through the learning process.

\subsection{Overview of Decision Support System for Aesthetic Design of Bridge Handrails System}

The user (decision maker) who wishes to create aesthetic designs of a bridge handrail inputs the following data for the bridge handrail to be designed: 
1. The design concepts.

2. The surrounding environment.

3. The configuration of the bridge.

4. The color of the bridge components other than the handrail.

An interactive input system is employed by selecting from items stored in it. Based on the input data two or more quasi-optimal solutions are searched and found using an immune algorithm and a neural network, and candidate aesthetic designs are presented. The flow of the processing by the system is shown in Fig. 6 .

One hundred and five photographs of existing bridge handrails are evaluated individually and the results are learned using the neural network. The touch of an expert can be acquired by making evaluation in this manner of bridge handrails that were designed by experts. Therefore, a near-expert level evaluation can be provided through the use of the neural network without an expert once the necessary knowledge is acquired through the learning process.

Then a search for two or more quasi-optimal solutions is made using the neural network that learned the necessary knowledge as an evaluation function for the immune algorithm. As mentioned above, immune algorithms are suitable for aesthetic designing because they allow two or more different quasi-optimal solutions rather than a single optimal solution to be obtained so that the human decision makers can select an appropriate candidate from them based on their subjective judgment and preferences.

\subsubsection{Aesthetic Design Items}

The surrounding environment, bridge configuration, colors (handrails and except handrails) and handrail components are employed as the aesthetic design items. The photographs of existing bridges are used as the data for the learning with the neural

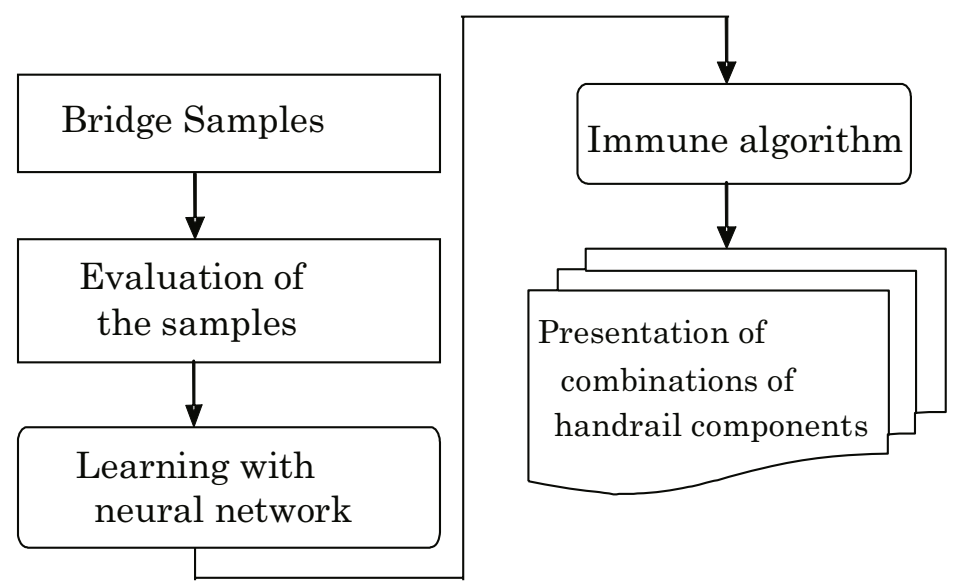

Fig. 6. Flow of the processing by the system 
network. Each of these photographs is treated as a sample (i.e. one learning data piece). Explanation of each of aesthetic parameters follows.

\subsubsection{Surrounding Environment}

The 14 kinds of surrounding environments assumed from the photographs were set up. These are shown in Table 1 In the genetic representation used in this system, 1 or 0 is used to indicate that each of the environmental components is present or not, respectively.

Table 1. Environmental factors

\begin{tabular}{c|c}
\hline Blue sky & Rice paddies \\
Cloudy & River \\
White clouds & Sea \\
Mountains (green leaves) & Urban area (buildings) \\
Mountains (brown leaves) & Residences (houses) \\
Mountains (red leaves) & Snow \\
Rock or soil & Pavement \\
\hline
\end{tabular}

\subsubsection{Bridge Configuration}

The classification of bridge configurations shown in Table 2 is used. The 105 samples are also broken down in Table 2 .

Table 2. Bridge configuration classification and sample number

\begin{tabular}{c|c}
\hline Bridge & Sample Number \\
\hline Girder bridge & 88 \\
Truss bridge & 2 \\
Arch bridge & 6 \\
Suspension bridge & 2 \\
Cable-stayed bridge & 5 \\
Rigid frame bridge & 2 \\
\hline
\end{tabular}

\subsubsection{Color of Bridge Components}

As the options for the "color of bridge components", the 16 colors are considered, which are close to the colors used for the handrails and other bridge components (girders, arch sections, etc.).

Table 3 shows these colors in 3 different color systems (the Mansell value system, the JIS and Japan Paint Manufacturers Association (JPMA) color systems) for ease of use. 
Table 3. Color options

\begin{tabular}{c|c|c}
\hline JIS & JPMA & Mansell \\
\hline Red & T07-40X & $7.5 \mathrm{R} 4 / 14$ \\
Brown & T15-30F & $5 \mathrm{YR} 3 / 3$ \\
Cream & T25-85F & $5 \mathrm{Y} 8.5 / 3$ \\
Celadon & T35-70H & $5 \mathrm{GY7} / 4$ \\
Jasper green & T37-50D & $7.5 \mathrm{GY} 5 / 2$ \\
Light greenish blue & T55-50P & $5 \mathrm{BG} / 8$ \\
Light blue & T65-80D & $5 \mathrm{~B} 8 / 2$ \\
Baby blue & T72-70D & $2.5 \mathrm{~PB} 7 / 2$ \\
Saxon gray & TN-50 & $\mathrm{N}-5$ \\
Dayflower & T69-50T & $10 \mathrm{~B} 5 / 10$ \\
Rose pink & T12-70L & $2.5 \mathrm{YR} 7 / 6$ \\
Snow white & TN-95 & $\mathrm{N}-9.5$ \\
Yellowish brown & T19-60F & $10 \mathrm{YR} 6 / 3$ \\
Sky gray & TN-80 & $\mathrm{N}-8$ \\
India ink & TN-10 & $\mathrm{N}-1$ \\
Silver & & \\
\hline
\end{tabular}

\subsubsection{Handrail Components}

In this system, bridge handrails are made up of upper, intermediate and lower bridge handrail components and bridge handrail columns. Each part was classified as shown in Fig. 7

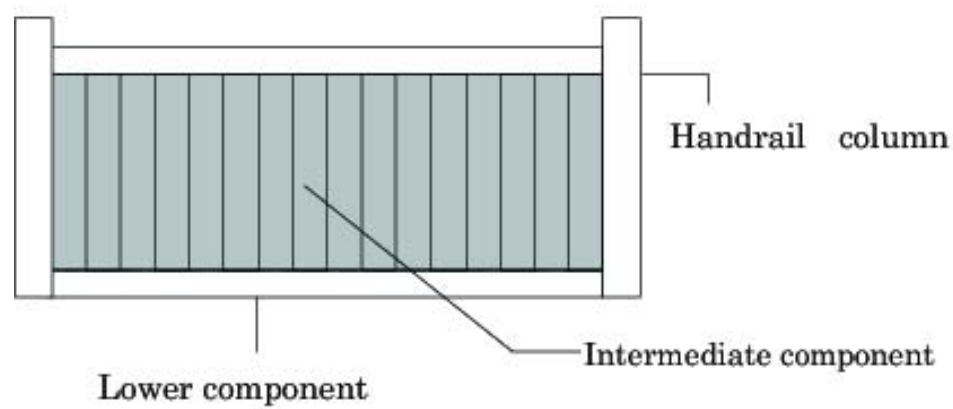

Fig. 7. Handrail components

\subsubsection{Design Concepts}

To realize the aesthetic design of bridges in this system, several concepts are prepared, which are summarized in Table 4 The user can select the desired design concepts. Two or more concepts can be selected. 
Table 4. Design concepts

\begin{tabular}{l}
\hline Symbolic value \\
Uniqueness \\
Reliability (Peaceful) \\
Friendly \\
Nobleness \\
Internationality \\
Harmony with the surrounding environment \\
\hline
\end{tabular}

\subsubsection{Evaluation}

105 photographs of the bridges that really exist are used for evaluation. The aesthetic parameters of each sample (photograph) were coupled with the corresponding data that were input into the neural network and were represented as a gene for the immune algorithm. Genes that represent aesthetic parameters in binary figures, i.e., 0 and 1 were used so that genetic codes are represented as one-dimensional bit rows.

1. Surrounding environment: 14 types, 14 bits.

2. Bridge configuration: 6 types, 3 bits.

3. Colors (handrails and bridge components other than handrails): 16 types, 4 bits.

4. Upper handrail components: 4 types, 2 bits.

5. Intermediate handrail components: 64 types, 6 bits.

6. Lower handrail components: 4 types, 2 bits.

7. Handrail columns: 16 types, 4 bits.

As shown in Fig 8, these are represented as 39-bit genes.

The genes shown in Fig 8 represent the following conditions:

1. Surrounding environment: blue sky, white clouds, mountains (green leaves), urban area (buildings), pavement.

2. Bridge configuration: girder bridge.

3. Color of bridge components other than bridge handrails: baby blue.

4. Color of bridge handrails: baby blue.

5. Handrail components: upper components: Type 1; intermediate components: Type 54; lower components: Type 1; handrail columns: Type 2.

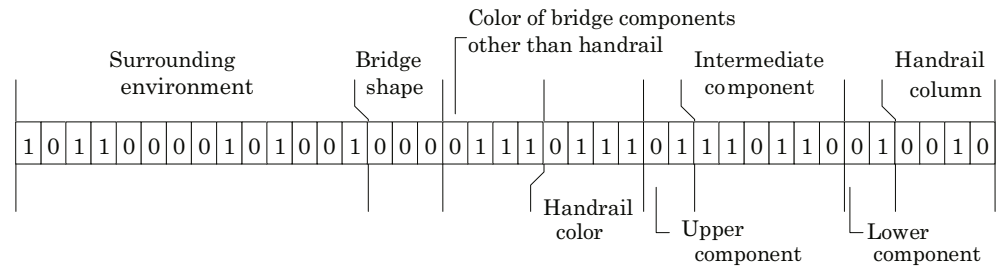

Fig. 8. Gene row of aesthetic parameters 
In the application of immune algorithm to a gene, the "surrounding environment", "bridge configuration" and "color of bridge components other than handrails" parameters are fixed to the values (options) selected by the system user.

Each bridge sample (photograph) is evaluated with respect to the degree to which it matches the design concepts selected out of the seven design concepts shown in Table 4, using an integer scale of zero to ten. The results are used as the training data for the neural network, which are used as the evaluation function for the immune algorithm after it has learned the necessary knowledge. The result of an evaluation of a sample may differ from another evaluation of the same sample made at a different time or on a different day or may become a different one when the order of the examination of the samples (photographs) is changed. Some fluctuations are inevitable because it is humans that make evaluations, but it is possible to make the range of fluctuation narrow by utilizing the knowledge of experts, who are more consistent than non-experts in making technical evaluations. It is also considered that looking through all samples before starting evaluations will help reduce fluctuations.

By having the neural network learn the results of samples evaluations (learning data), it becomes possible to evaluate the data about which learning has not been done. Thus by using the neural network that learned the necessary knowledge as the evaluation function for the immune algorithm, new data can be evaluated to obtain two or more quasi-optimal solutions.

The neural network outputs the evaluation result for the selected design concepts, and the total of the evaluation values for the target design concepts is used as the evaluation value for the candidate of aesthetic design. In the neural computing the following parameters are used:

1. Number of layers of the network: 3

2. Number of patterns learned: 105

3. Number of first layer units: 39

4. Number of second layer units: 46

5. Number of third layer units: 7

6. Number of learning runs (integer value): 1000000

7. Allowable error range (real number value): 0.0000001

8. Learning coefficient (real number value): 0.9

9. Inertia coefficient (real number value): 0.6

10. Gradient of sigmoid function: 1.0

\subsubsection{Application Example}

The immune algorithm parameters were set as follows:

1. Initial number of antibodies: 20 (gene of the initial antibodies-generation of random number as binary figures 0,1$)$.

2. Upper limit for the number of memory cells: 5 .

3. Number of generations: 300 .

4. Manipulation of crossover: uniform crossover, crossover rate: 70 .

5. Manipulation of mutation: reversing of a selected bit, mutation rate: 0.3. 
6. Thresholds: $\mathrm{Tc}=0.8, \mathrm{Tac} 1=0.8, \operatorname{Tac} 2=0.7, \mathrm{Tac} 3=0.8, \mathrm{Tac} 4=0.88$.

7. Suppress power: 1 .

Examples of actual application of the present system are described as follows.

\subsubsection{Design Case 1}

1. Surrounding environment: blue sky, white clouds, mountains (green leaves), mountains (brown leaves), rock or soil, river, residence (houses), pavement.

2. Bridge configuration: girder bridge.

3. Color of bridge components other than handrails: cream $((\mathrm{T} 25-85 \mathrm{~F}) /(5 \mathrm{Y} 8.5 / 3))$.

4. Design concepts: friendly, harmony with the surrounding environment.

Under the above conditions, five design candidates are obtained as shown in Table 5 Table 5 shows that the present system provided five design plans with different characteristics. It is seen that the color selected for the handrail is calm and unremarkable and the configuration of the handrail is simple so that all the plans are satisfactory for such design concepts as "friendly" and "harmony with the surrounding environment".

Table 5. Design candidates for Case 1

\begin{tabular}{c|c|c|c|c|c}
\hline & Plan 1 & Plan 2 & Plan 3 & Plan 4 & Plan 5 \\
\hline Color of handrail & Yellowish brown & Sky gray & Brown & Brown gray & Brown gray \\
Upper component & Type 2 & Type 1 & Type 1 & Type 1 & Type 3 \\
Middle component & Type 7 & Type 3 & Type 3 & Type 1 & Type 35 \\
Lower component & Type 2 & Type 2 & Type 2 & Type 2 & Type 0 \\
Column & Type 2 & Type 0 & Type 10 & Type 10 & Type 10 \\
Friendly & 0.8 & 0.9 & 0.8 & 0.9 & 0.8 \\
Harmony & 0.9 & 0.9 & 0.9 & 0.8 & 0.8 \\
\hline
\end{tabular}

\subsubsection{Design Case 2}

1. Surrounding environment: blue sky, white clouds, mountains (green leaves), mountains (brown leaves), rock or soil, river, residence, pavement.

2. Bridge configuration: girder bridge.

3. Color of bridge components other than handrails: cream $((\mathrm{T} 25-85 \mathrm{~F}) /(5 \mathrm{Y} 8.5 / 3))$.

4. Design concepts: unique, harmony with the surrounding environment.

Design Case 2 is the same as Design Case 1 except that the design concept "unique" is used in place of the "friendly". Table 6 presents the design plans obtained by the present system. As shown in Table 6, the configuration of the handrail becomes complicated compared with that of Case 1. The larger the type number of handrail elements is, the more complicated the configuration of handrail becomes. In addition, the color obtained for Plan 3 is red that is not chosen for Case 1. Regarding the design concepts, the second concept of "harmony" is difficult to get high score, when the plan shows the good match to the first concept of "unique", because these two concepts have contradictory characteristics. Thus, this result is considered to be reasonably satisfactory. 
Table 6. Design candidates for Case 2

\begin{tabular}{c|c|c|c|c|c}
\hline & Plan 1 & Plan 2 & Plan 3 & Plan 4 & Plan 5 \\
\hline Color of handrail & Saxon gray & Sky gray & Red & Brown & Brown \\
Upper component & Type 1 & Type 1 & Type 2 & Type 0 & Type 2 \\
Middle component & Type 45 & Type 47 & Type 61 & Type 63 & Type 37 \\
Lower component & Type 0 & Type 2 & Type 0 & Type 0 & Type 0 \\
Column & Type 2 & Type 2 & Type 2 & Type 6 & Type 3 \\
Unique & 1.0 & 0.9 & 1.0 & 1.0 & 1.0 \\
Harmony & 0.6 & 0.8 & 0.7 & 0.6 & 0.6 \\
\hline
\end{tabular}

\subsubsection{Design Case 3}

1. Surrounding environment: blue sky, white clouds, mountains (green leaves), mountains (brown leaves), rock or soil, river, residence (houses), pavement.

2. Bridge configuration: girder bridge.

3. Color of bridge components other than handrails: cream $((\mathrm{T} 25-85 \mathrm{~F}) /(5 \mathrm{Y} 8.5 / 3))$.

4. Design concepts: internationality, harmony with the surrounding environment.

Design Case 3 has the same design requirements except the design concept: "internationality", whereas "friendly" in Case 1 and "unique" in Case 2. Table 7 presents the design plans obtained for Case 3. By changing the design concept from "friendly" to "internationality", five design plans different from those of Case 1 and Case 2 are obtained. As shown in Table 7 there are more color variations than in Case 1 and the components are different from those used in Case 1, but it is rather debatable whether these candidates of aesthetic designs have internationality. It had been anticipated that intermediate handrail components with European looks would be selected, but in reality relatively simple ones were selected. Also, the colors return to calm ones.

Table 7. Design candidates for Case 3

\begin{tabular}{c|c|c|c|c|c}
\hline & Plan 1 & Plan 2 & Plan 3 & Plan 4 & Plan 5 \\
\hline Color of handrail & Sky gray & Light-greenish blue & Silver & Baby blue & Silver \\
Upper component & Type 3 & Type 3 & Type 1 & Type 2 & Type 0 \\
Middle component & Type 3 & Type 19 & Type 39 & Type 7 & Type 1 \\
Lower component & Type 2 & Type 0 & Type 3 & Type 2 & Type 2 \\
Column & Type 2 & Type 10 & Type 10 & Type 8 & Type 2 \\
Internationality & 0.7 & 0.6 & 0.8 & 0.8 & 0.9 \\
Harmony & 0.9 & 0.8 & 0.7 & 0.8 & 0.6 \\
\hline
\end{tabular}

\subsubsection{Design Case 4}

1. Surrounding environment: blue sky, white clouds, river, urban area (buildings).

2. Bridge configuration: girder bridge. 
3. Color of bridge components other than handrails: cream $((\mathrm{T} 25-85 \mathrm{~F}) /(5 \mathrm{Y} 8.5 / 3))$.

4. Design concepts: internationality, harmony with the surrounding environment.

Design Case 4 is almost the same as Design Case 3 except for the "surrounding environment", which is changed from the "residence" to "business area". Table 8 presents the candidates of aesthetic design obtained for Case 4 . The evaluation values are higher than those given in Case 3 for both "internationality" and "harmony with the surrounding environment". This shows that different results can be obtained only by changing the surrounding environment parameter setting. The handrail components used are little different from those used in Case 3, but the colors are almost the same as those used in Case 3.

Table 8. Design candidates for Case 4

\begin{tabular}{c|c|c|c|c|c}
\hline & Plan 1 & Plan 2 & Plan 3 & Plan 4 & Plan 5 \\
\hline Color of handrail & Baby blue & Silver & Baby blue & Light-greenish blue & Silver \\
Upper component & Type 0 & Type 0 & Type 2 & Type 0 & Type 2 \\
Middle component & Type 21 & Type 3 & Type 8 & Type 1 & Type 33 \\
Lower component & Type 1 & Type 3 & Type 0 & Type 2 & Type 1 \\
Column & Type 2 & Type 8 & Type 10 & Type 2 & Type 10 \\
Internationality & 1 & 1 & 0.9 & 1 & 1 \\
Harmony & 0.8 & 0.9 & 1 & 0.9 & 0.9 \\
\hline
\end{tabular}

\subsubsection{Design Case 5}

1. Surrounding environment: blue sky, white clouds, mountains (green leaves), mountains (brown leaves), rock or soil, river, residence (houses), pavement.

2. Bridge configuration: girder bridge.

3. Color of bridge components other than handrails: jasper green ((T37-50D)/(7.5GY5/2)).

4. Design concepts: friendly, harmony with the surrounding environment.

This application example is the same as Design Case 1 except that "jasper green" is used in place of the "cream" as the color of bridge components other than the handrails.

Table 9. Design candidates for Case 5

\begin{tabular}{c|c|c|c|c|c}
\hline & Plan 1 & Plan 2 & Plan 3 & Plan 4 & Plan 5 \\
\hline Color of handrail & Sky gray & Brown gray & Jasper green & Brown gray & Sky gray \\
Upper component & Type 1 & Type 1 & Type 3 & Type 3 & Type 1 \\
Middle component & Type 3 & Type 3 & Type 38 & Type 7 & Type 23 \\
Lower component & Type 3 & Type 2 & Type 2 & Type 2 & Type 2 \\
Column & Type 2 & Type 0 & Type 10 & Type 0 & Type 10 \\
Friendly & 0.8 & 0.9 & 0.8 & 0.8 & 0.8 \\
Harmony & 0.9 & 0.9 & 0.9 & 0.8 & 0.9 \\
\hline
\end{tabular}


The colors obtained are calm and unremarkable, and the configuration of the handrail is rather simple. It can be said that the candidates of aesthetic design provide similar atmospheres to those provided by the candidates of aesthetic design in Case 1 and thus match the design concepts selected.

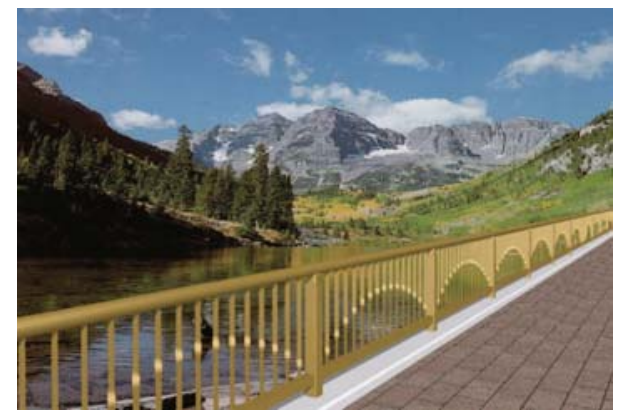

Fig. 9. Plan 1 of Design Case 1

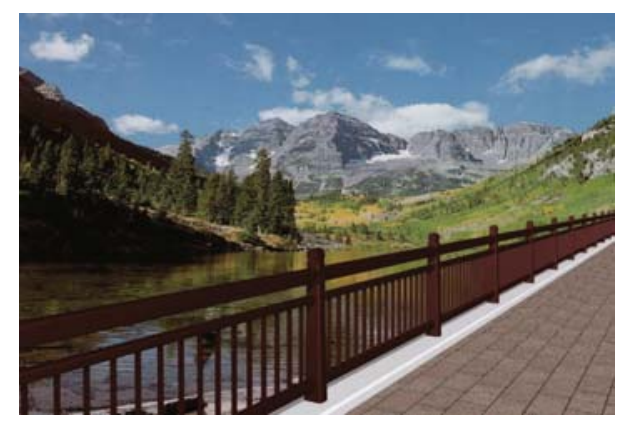

Fig. 10. Plan 3 of Design Case 1

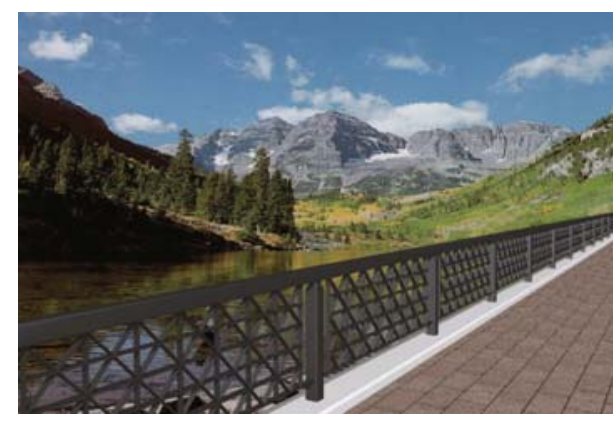

Fig. 11. Plan 1 of Design Case 2 


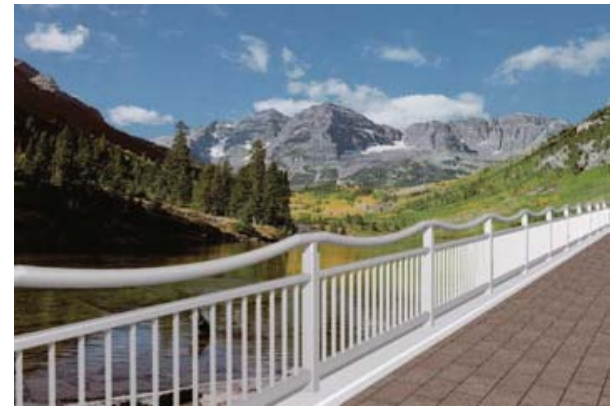

Fig. 12. Plan 1 of Design Case 3

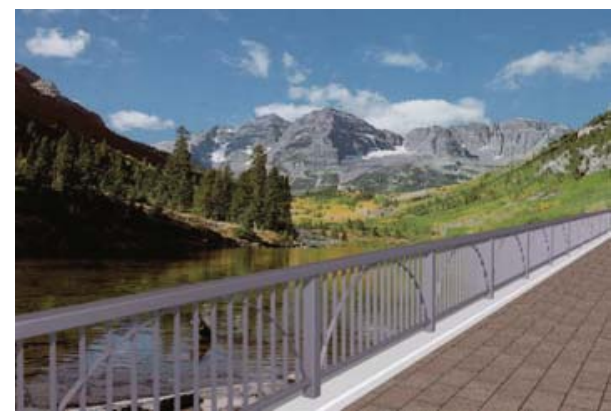

Fig. 13. Plan 1 of Design Case 4

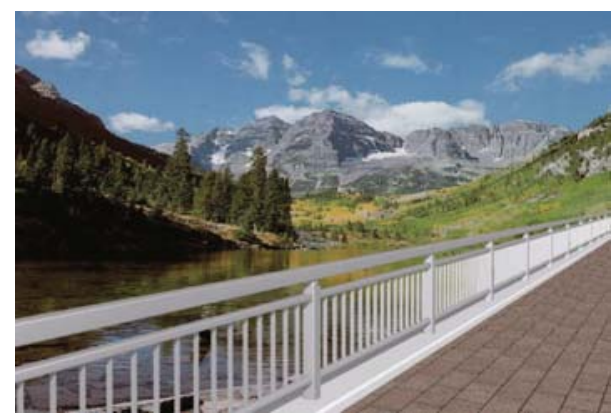

Fig. 14. Plan 1 of Design Case 5 


\subsubsection{Visualization of Application Example Using Computer Graphics}

Some of the candidates of aesthetic design presented by the system in the application example were compared mutually using figures visualized by computer graphics. Plans 1 of Design Cases 1 to 5 and Plan 3 of Design Case 1 were selected to be visualized (a total of 6 plans). To facilitate comparison, the same background was used for all of the plans selected. The visualized candidates of aesthetic design are shown in Figs. 9 to 14

The plans shown in Figs. 9 and 10 are ones from the same application example (Design Case 1). Although these plans have different features, it is considered that they are ones with similar atmospheres because both of them seem to match the design concepts selected.

The candidate of aesthetic design shown in Fig.11 is a plan from Case 2, which is the same as Case 1 except that the concept "unique" is used in place of the "friendly". It is considered that the plan matches the design concept "unique" because the intermediate handrail components have a more complex shape than those of the intermediate handrail components shown in Figs. 9 and 10 and the evaluation value is high.

The plan shown in Fig. 12 is a plan from Case 3, which is the same as Case 1 except that the concept "internationality" is used in place of the "friendly". This plan may appear to have an international appearance at a first glance in the sense that the handrail color and the shape of the upper handrail components are more uncommon than those used in Figs. 9 and 10, but it is debatable whether this plan has an international appearance because the shape of the intermediate handrail components is rather simple.

The plan (candidate of aesthetic design) shown in Fig. 13 is a plan from Case 4, which is the same as Case 3 except that the surrounding environment is different. It is not possible to compare Fig. 12 with Fig. 13 in terms of the surrounding environment because the same background is used. However, it is considered that this plan matches the design concept "internationality" because the evaluation point is high.

The plan shown in Fig. 14 is a plan from Case 5, which is the same as Case 1 except that "jasper green" is used in place of the "cream" as the color of the bridge components other than the bridge handrails. Although the plans shown in Figs. 9 , 10 and 14 have different features, it is considered that they are ones with similar atmospheres because they match the design concepts selected.

\section{Optimal Restoration Scheduling for Earthquake Disaster}

Japan has been suffering from many natural disasters such as typhoons, tsunami and earthquakes. However, road networks have not been designed to protect against all such natural hazards. Moreover, even the newest design theory cannot guarantee the absolute safety due to the economic constraints. Therefore, it is necessary to develop a synthetic disaster prevention program based on the recognition that road networks may be unavoidably damaged when big earthquakes occur.

In this paper, the early restoration of road networks after the earthquake disasters is focused on. Three issues are dealt with, the first of which is an allocation problem: which groups restore which disaster places, the second is a scheduling problem: what 
order is the best for the restoration, and the third is an allocation problem: which restoring method is suitable for which disaster places. In order to solve the three problems simultaneously, Genetic Algorithm (GA) is applied, because it has been proven to be very powerful in solving combinatorial problems. In this paper, the relationships among early restoration, minimization of Life-Cycle Cost (LCC), and target safety level of road network are discussed by using Multi-Objective Genetic Algorithm (MOGA). Namely, the following three objective functions are considered:

1. Restoring days are minimized.

2. LCC is minimized.

3. Performance level of road network is maximized.

Then, it is possible to solve the multi-objective optimization problem by making two of the three objective functions as the constrained conditions. For example, the minimization of restoring days is required according to the prescribed performance level and LCC constraints. The predetermination of these requirements may be detrimental. Namely, taking the same restoring days, it may be possible to find solutions that can largely reduce the LCC if the performance level can be slightly decreased. Alternatively, taking the same restoring days, it may be possible to find solutions that can substantially increase the performance level if the LCC is slightly increased.

By introducing the concept of multi-objective optimization into the restoration scheduling for earthquake disasters, it is intended to find several near-optimal restoration scheduling plans. Although single-objective optimization can provide various solutions by changing the constraints, it requires enormous computation time. When selecting a practical restoration schedule, it is desirable to compare feasible optional solutions obtained under various conditions. Thus, a decision support system that can provide several alternative restoration schedules was developed by applying MOGA. Several numerical examples are presented to demonstrate the applicability and efficiency of the present method.

\subsection{Road Network Models}

Here, it is assumed that a road network is damaged, in which multiple portions are suffered from damage so that it cannot function well. The objective is the realization of quick restoration of the lifeline system. It is intended to determine the optimal allocation of restoring teams and optimal scheduling of restoring process, and optimal allocation of restoring methods. Then, the following conditions should be taken into account:

1. The optimal allocation of restoring teams, optimal scheduling of restoring process, and optimal allocation of restoring methods must be determined simultaneously.

2. A portion of the road network is suffered from several kinds of damage that have a hierarchical relation in time.

As an example of restoration, a road network is considered, which has 164 nodes as shown in Fig. 15. This model corresponds to an area damaged by the 1995 Kobe 


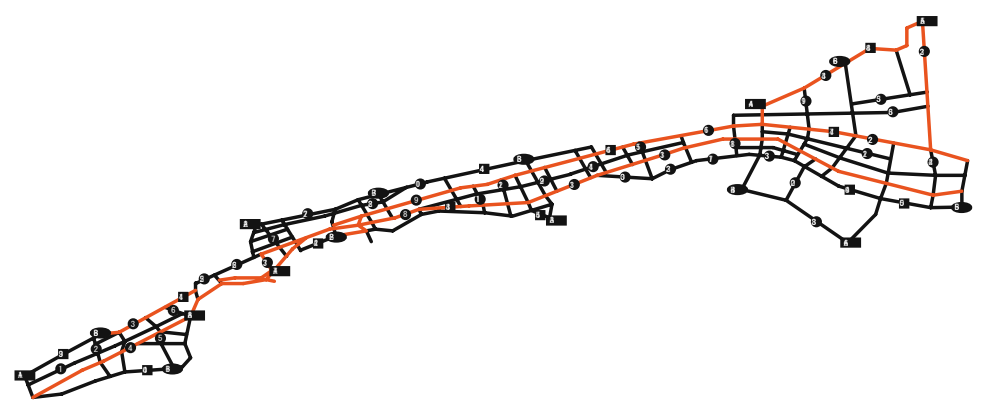

Fig. 15. Road network model

Table 10. Data of work $(A)$

\begin{tabular}{c|cc}
\hline \hline Team of work $(A)$ & Ability Previous works before scheduling \\
\hline 1 & 15 & 0 \\
2 & 30 & 0 \\
3 & 12 & 0 \\
4 & 17 & 37 \\
5 & 18 & 0 \\
6 & 23 & 36 \\
7 & 25 & 0 \\
8 & 35 & 38 \\
\hline
\end{tabular}

Table 11. Data of work $(B)$

\begin{tabular}{c|cc}
\hline Team of work $(B)$ & Ability Previous works before scheduling \\
\hline 1 & 15 & 43 \\
2 & 20 & 46 \\
3 & 25 & 48 \\
4 & 10 & 0 \\
5 & 17 & 0 \\
6 & 30 & 49 \\
7 & 23 & 0 \\
8 & 27 & 0 \\
\hline
\end{tabular}

earthquake. For this road network, the following restoration works are necessary to recover the function:

1. Work $(A)$ : work to clear the interrupted things, 38 sites $(1-38)$

2. Work $(B)$ : work to restore the roads, 50 sites $(1-50)$ 
Table 12. Work $(A)$ 's damage level and rank of importance

\begin{tabular}{c|cc||c|cc}
\hline Link & Damage level Rank of importance & Link & Damage level Rank of importance \\
\hline 1 & 242 & 1 & 20 & 582 & 1 \\
2 & 223 & 2 & 21 & 542 & 1 \\
3 & 625 & 3 & 22 & 451 & 3 \\
4 & 312 & 3 & 23 & 434 & 3 \\
5 & 554 & 1 & 24 & 311 & 3 \\
6 & 514 & 1 & 25 & 441 & 2 \\
7 & 311 & 1 & 26 & 412 & 2 \\
8 & 473 & 3 & 27 & 531 & 2 \\
9 & 300 & 3 & 28 & 156 & 2 \\
10 & 321 & 3 & 29 & 556 & 1 \\
11 & 656 & 1 & 30 & 520 & 2 \\
12 & 380 & 1 & 31 & 551 & 3 \\
13 & 501 & 3 & 32 & 166 & 1 \\
14 & 302 & 1 & 33 & 513 & 1 \\
15 & 312 & 3 & 34 & 531 & 3 \\
16 & 321 & 3 & 35 & 495 & 1 \\
17 & 231 & 1 & 36 & 424 & 1 \\
18 & 534 & 2 & 37 & 337 & 3 \\
19 & 171 & 1 & 38 & 564 & 2 \\
\hline
\end{tabular}

Then, the limitations and restrictions of each work should be considered, for instance, work $(B)$ should be done after work $(A)$. Work $(B)$ consists of the following three works: work to repair the roads, work to reinforce the roads and work to rebuild the roads. The waiting places of restoring teams for work $(A)$ and work $(B)$ are shown by the numbers A (1-8) and B (1-8), respectively. Tables 10 and 11 show the ability to restore and the previous works before scheduling of each team. Tables 12 and 13 show the damage level and the rank of importance.

\subsection{Restoration Scheduling}

Weighting factors are prescribed for the links with damage, which are denoted by $W_{i}\left(i=1, \ldots, n_{L}\right) . n_{L}$ is the total number of damaged links. Then, the restoring rate after $q$ days, $R^{(q)}$, is expressed as follows:

$$
R^{(q)}=\frac{\sum_{i \in J^{(q)}} W_{i} \times l_{i}}{\sum_{i \in J^{(0)}} W_{i} \times l_{i}}
$$

where $l_{i}$ is the distance of the $i$-th link, $J^{(0)}$ is the set of damaged links, $J^{(q)}$ is the set of restored links until $q$ days after the disaster, and $W_{i}$ is the weighting factor of the 
Table 13. Work $(B)$ 's damage level and rank of importance

\begin{tabular}{c|cc||c|cc}
\hline Link & Damage level Rank of importance & Link & Damage level Rank of importance \\
\hline 1 & 153 & 1 & 26 & 146 & 2 \\
2 & 453 & 2 & 27 & 366 & 2 \\
3 & 496 & 3 & 28 & 311 & 2 \\
4 & 464 & 3 & 29 & 145 & 1 \\
5 & 133 & 1 & 30 & 425 & 2 \\
6 & 415 & 1 & 31 & 413 & 3 \\
7 & 355 & 1 & 32 & 231 & 1 \\
8 & 531 & 3 & 33 & 245 & 1 \\
9 & 246 & 3 & 34 & 353 & 3 \\
10 & 623 & 3 & 35 & 461 & 1 \\
11 & 445 & 1 & 36 & 131 & 1 \\
12 & 154 & 1 & 37 & 455 & 3 \\
13 & 613 & 3 & 38 & 564 & 2 \\
14 & 444 & 1 & 39 & 631 & 1 \\
15 & 366 & 3 & 40 & 322 & 2 \\
16 & 615 & 3 & 41 & 464 & 3 \\
17 & 641 & 1 & 42 & 114 & 1 \\
18 & 151 & 2 & 43 & 415 & 1 \\
19 & 254 & 1 & 44 & 700 & 1 \\
20 & 654 & 1 & 45 & 311 & 3 \\
21 & 561 & 1 & 46 & 211 & 3 \\
22 & 125 & 3 & 47 & 344 & 3 \\
23 & 345 & 3 & 48 & 407 & 3 \\
24 & 462 & 3 & 49 & 512 & 2 \\
25 & 456 & 2 & 50 & 423 & \\
\hline
\end{tabular}

$i$-th link. Then, the objective function can be calculated by using the restoring days and the restoring rate. The relation between restoring days and restoring rate is shown in Fig. 16. The area of the uncolored portion should be minimized to obtain the optimal solution, because this enables not only to shorten the restoring days but also to restore the important links faster.

Restoring days are calculated for each restoring work, and the minimum days necessary for each work is given as

$$
d=\frac{h}{t_{1}}
$$

where $h$ is the restoration time required to complete the restoration work.

In this paper, the restoration time is calculated by using the restoration rate for each work and the capability value. The relation between the restoration rate for each work and the capability of the teams are shown in Fig. 17. The restoration rate is given as follows: 
a) Small damage: In the small damage, there is no difference in capability of each team. The restoration will be completed during a fixed time. Here, 4 hours are assumed.

$$
h=h_{t}
$$

b) Moderate damage: In the moderate damage, there are some differences in capability between teams. However, every team can restore the damage.

$$
h=\frac{D}{A}
$$

where $D$ is the amount of damage and $A$ is the capability of the team, that is, the restoring amount per hour.

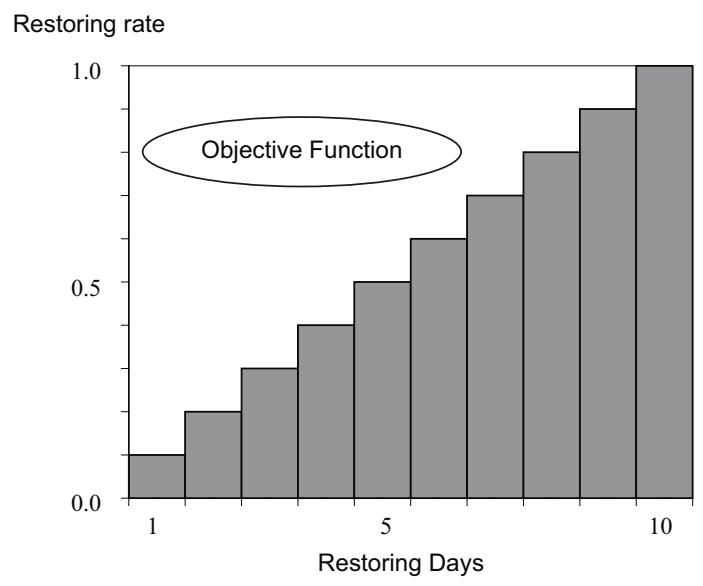

Fig. 16. Objective function

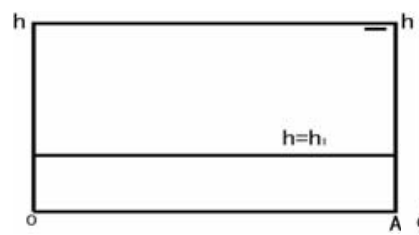

a) Small damage

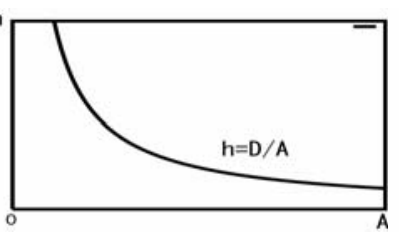

b) Moderate damage

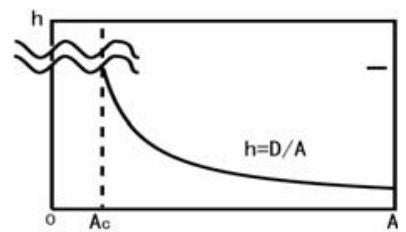

c) Large damage

Fig. 17. Relations between restoration rate for each work and capability of teams 
c) Large damage: In the large damage, only some teams can restore, because other teams have no restoring equipment and facility necessary for the large damage.

$$
h= \begin{cases}\infty, & \text { if } A<A_{c}, \\ D / A, & \text { if } A \geq A_{c} .\end{cases}
$$

where $A_{c}$ is the minimum capability which the team can work.

The working hours per day of a restoration team are calculated by Equation (6), where $t_{m}$ is the moving time to a site given by Equation (7). The shortest distance from the waiting place of the restoration team to the site is considered as $L(\mathrm{~km})$, and the moving speed of the team is set to be $v(\mathrm{~km} / \mathrm{h}) . h_{c}$ is the preparation time that is necessary for every work.

$$
\begin{gathered}
t_{1}=t_{0}-2 t_{m}-h_{c} \\
t_{m}=\frac{L}{v}
\end{gathered}
$$

\subsection{Optimal Restoration Scheduling for Earthquake Disaster Using Life-Cycle Cost}

Road networks have not been designed to sustain all natural hazards. Moreover, even the newest design theory cannot guarantee the absolute safety due to the economic constraints. Therefore, it is necessary to develop a synthetic disaster prevention program based on the recognition that road networks may be unavoidably damaged when big earthquakes occur. The purpose of this research is the early restoration of road networks after the earthquake disasters. Three issues are focused on, the first of which is an allocation problem: which groups restore which disaster places, the second is a scheduling problem: what order is the best for the restoration, and the third is an allocation problem: which restoring method is suitable for which disaster places. In order to solve the three problems simultaneously, Genetic Algorithm (GA) is applied. In this paper, an attempt is made to discuss the relationships among early restoration, minimization of LCC, and target safety level of road network by using Multi-Objective Genetic Algorithm (MOGA). Namely, the following three objective functions are considered:

1. Restoring days are minimized.

2. LCC is minimized.

3. Target safety level of road network is maximized.

Then, it is possible to solve the multi-objective optimization problem by making two of the three objective functions as the constrained conditions. For example, the minimization of restoring days is required according to the prescribed target safety level and LCC constraints. The predetermination of these requirements may be detrimental. Namely, taking the same restoring days, it may be possible to find solutions that can 
largely reduce the LCC if the safety level can be slightly decreased. Alternatively, taking the same restoring days, it may be possible to find solutions that can substantially increase the safety level if the LCC is slightly increased.

By introducing the concept of multi-objective optimization into the restoration scheduling for earthquake disasters, it is intended to find several near-optimal restoration schedules. Although single-objective optimization can provide various solutions by changing the constraints, it requires enormous computation time. When selecting a practical restoration schedule, it is desirable to compare feasible optional solutions obtained under various conditions. Thus, an attempt is made in this study to develop a decision support system that can provide several alternative restoration schedules by applying MOGA.

\subsection{Objective Functions}

In this study, restoring days, LCC and safety level are used as objective functions. Restoring days are minimized, LCC is minimized, and safety level is maximized. There are trade-off relations among the three objective functions. For example, safety level decreases when LCC decreases, and safety level is extended due to the extension of restoring days. Then, multi-objective optimization can provide a set of Pareto solutions that cannot improve an objective function without making other objective functions worse. In this study, DNA structure is constituted as shown in Fig. 18, in which DNA of each individual consists of three parts such as restoring method, allocation of restoring teams, and schedule of restoring process. Using the coding, it is possible to determine the optimal allocation of restoring teams, optimal scheduling of restoring process, and optimal allocation of restoring methods simultaneously.

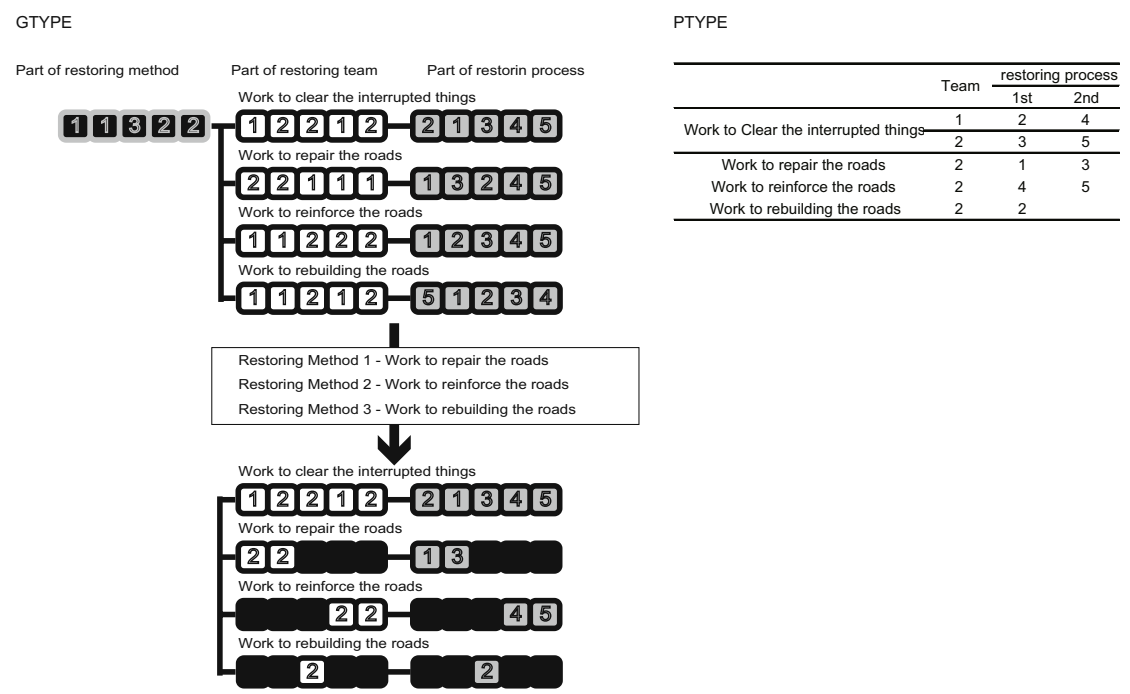

Fig. 18. DNA structure 
Then, the three objective functions are expressed as follows.

\subsubsection{Restoring Days}

The relation between restoring days and restoring rate is shown in Fig. 16 The area of the uncolored portion should be minimized to obtain the optimal solution, because this enables not only to shorten the restoring days but also to restore the important links faster.

\subsubsection{Life-Cycle Cost}

Life-Cycle Cost $(L C C)$ is defined as the total maintenance cost in terms of road network and all the entire bridges during their lives. In this paper, restoring method is defined by three kinds of methods: work to repair the roads, work to reinforce the roads, and work to rebuild the roads. Then, restoring cost of each work is defined by

$$
R C=C_{b} \times D_{\text {degree }}
$$

where $C_{b}$ is the basic restoring cost and $D_{\text {degree }}$ is the level of damage defined in Table 14. Table 15 presents the basic costs and safety levels by the restoring methods. Fig. 19 shows the performance levels of restoring methods. Maintenance cost of each work after restoring is defined by

$$
M C=M_{b} \times D_{r}
$$

where $M_{b}$ is the basic maintenance cost presented in Table 15 and $D_{r}$ is the level of deterioration defined in Table 14. Here, the accumulated maintenance cost is considered for 50 years.

Then, the objective function is defined by

$$
L C C=\sum_{i \in J^{(0)}}\left(R C_{i}+M C_{i}\right)
$$

where $R C_{i}$ is the restoring cost of the $i$-th link, $M C_{i}$ is the maintenance cost of the $i$-th link, and $J^{(0)}$ is the set of damaged links.

\subsubsection{Safety Level}

Safety level depends on the traffic volume and the condition of links. In this research, safety level $(S L)$ of the road network is maximized, which is defined by

$$
S L=\sum_{i \in J^{(0)}}\left(I_{i}+S L_{i}\right)
$$

where $I_{i}$ is the importance of the $i$-th link, $S_{i}$ is the safety level of the $i$-th link, and $J^{(0)}$ is the set of damaged links. 
Table 14. Levels of damage and levels of deterioration

\begin{tabular}{|c|c|c|c|c|c|c|c|}
\hline Link & Work $(A)$ & Work $(B)$ & Level of deterioration & Link & Work $(A)$ & Work $(B)$ & Level of deterioration \\
\hline 1 & 1.70 & 0.47 & 0.8 & 26 & 1.36 & 0.45 & 1.2 \\
\hline 2 & 0.73 & 0.96 & 1.0 & 27 & 1.33 & 1.12 & 1.2 \\
\hline 3 & 1.91 & 1.61 & 1.5 & 28 & 0.95 & 1.87 & 1.2 \\
\hline 4 & 0.94 & 1.42 & 1.5 & 29 & 1.33 & 0.44 & 0.8 \\
\hline 5 & 1.96 & 0.41 & 1.0 & 30 & 1.26 & 1.30 & 1.0 \\
\hline 6 & 1.53 & 1.27 & 0.8 & 31 & 1.65 & 1.26 & 1.5 \\
\hline 7 & 0.63 & 1.09 & 0.8 & 32 & 0.50 & 0.71 & 1.0 \\
\hline 8 & 1.38 & 1.62 & 1.5 & 33 & 1.54 & 0.75 & 0.8 \\
\hline 9 & 1.97 & 0.75 & 1.5 & 34 & 1.59 & 1.08 & 1.5 \\
\hline 10 & 1.02 & 1.91 & 1.5 & 35 & 0.74 & 1.10 & 1.0 \\
\hline 11 & 2.00 & 1.36 & 1.0 & 36 & 1.27 & 0.40 & 1.0 \\
\hline 12 & 1.27 & 0.47 & 1.0 & 37 & 1.01 & 0.78 & 1.5 \\
\hline 13 & 1.56 & 1.87 & 1.5 & 38 & 1.69 & 1.72 & 1.8 \\
\hline 14 & 0.94 & 1.36 & 1.0 & 39 & & 1.93 & 0.8 \\
\hline 15 & 0.97 & 1.12 & 1.2 & 40 & & 0.98 & 1.9 \\
\hline 16 & 0.71 & 1.88 & 1.2 & 41 & & 1.42 & 1.5 \\
\hline 17 & 0.74 & 1.96 & 1.0 & 42 & & 0.35 & 0.8 \\
\hline 18 & 2.00 & 0.46 & 1.0 & 43 & & 1.27 & 0.8 \\
\hline 19 & 1.87 & 0.78 & 0.8 & 44 & & 2.14 & 0.8 \\
\hline 20 & 0.94 & 2.00 & 0.8 & 45 & & 1.56 & 1.8 \\
\hline 21 & 0.67 & 1.72 & 0.8 & 46 & & 0.65 & 1.5 \\
\hline 22 & 1.56 & 0.38 & 1.2 & 47 & & 1.05 & 1.5 \\
\hline 23 & 0.49 & 1.06 & 1.2 & 48 & & 1.24 & 1.5 \\
\hline 24 & 1.67 & 0.65 & 1.5 & 49 & & 1.57 & 1.0 \\
\hline 25 & 1.63 & 1.64 & 1.0 & 50 & & 1.29 & 1.0 \\
\hline
\end{tabular}

Work $(A)$ : The level of damage for work to clear the interrupted things Work $(B)$ : The level of damage for work to restoring the roads

Table 15. The basic costs and safety levels by the restoring methods

\begin{tabular}{c|ccc}
\hline Restoring method & Basic restoring cost & Basic maintenance cost & Safety level \\
\hline Repair & 700 & 3500 & 0.6 \\
Reinforcement & 1200 & 2000 & 0.8 \\
Rebuilding & 5000 & 1500 & 0.9 \\
\hline
\end{tabular}

Basic restoring cost (Ten thousand yen)

Basic maintenance cost (Ten thousand yen)

\subsection{Multi-objective Optimization}

A multi-objective optimization problem has two or more objective functions that cannot be integrated into a single objective function. In general, the objective functions cannot be simultaneously minimized (or maximized). It is the essence of the problem that trade-off relations exist among the objective functions. The concept of "Pareto optimum" becomes important in order to balance the trade-off relations. The Pareto 


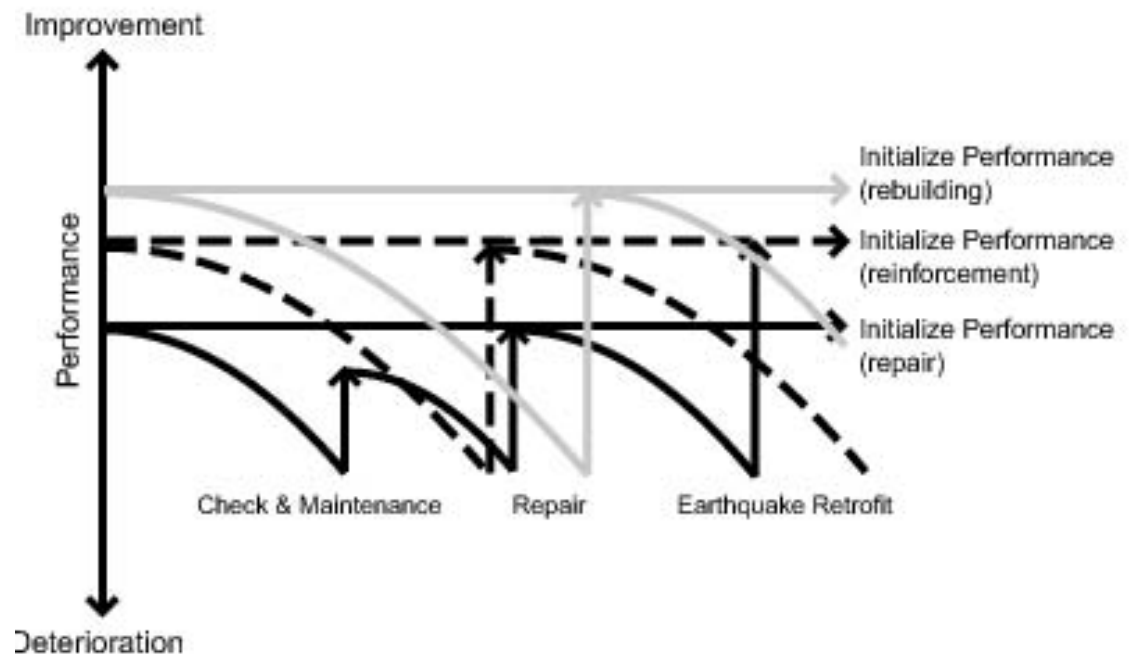

Fig. 19. The performance levels of restoring methods

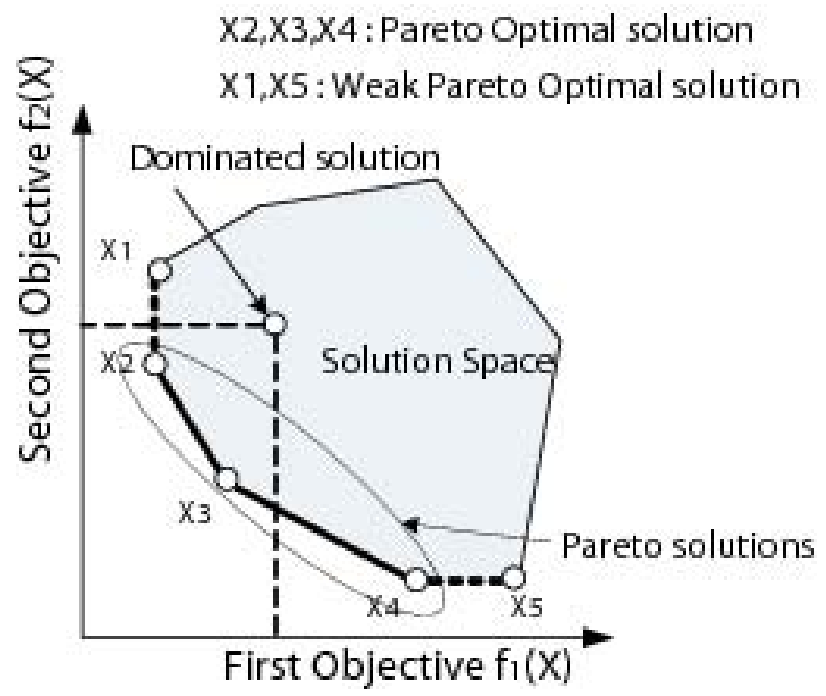

Fig. 20. Cost-effective domain including Pareto solutions 


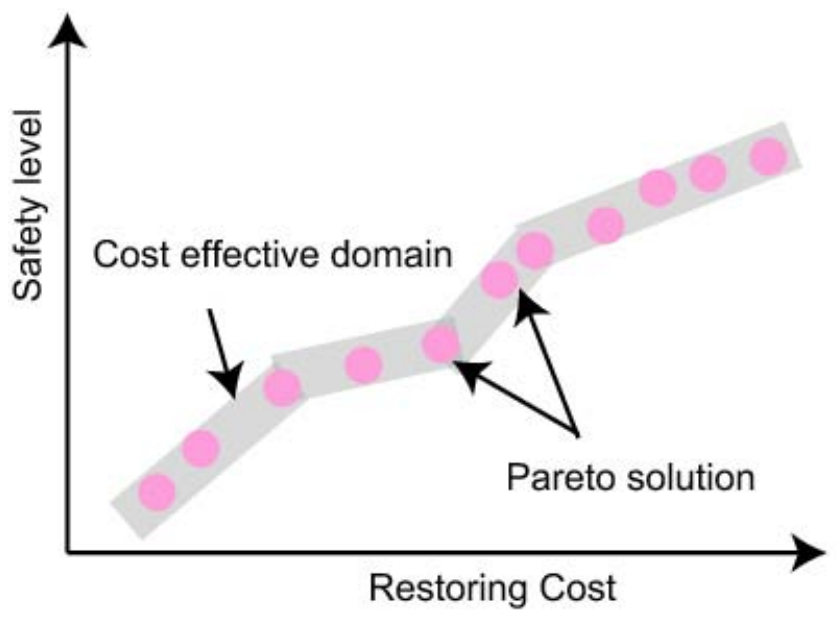

Fig. 21. Pareto solutions in objective space

optimum solution is a solution that cannot improve an objective function without sacrificing other functions (Figs. 20 and21). A dominated, also called non-dominant, solution is indicated in Fig. 20. GA is an evolutionary computing technique, in which candidates of solutions are mapped into GA space by encoding. The following steps are used to obtain the optimal solutions: a) initialization, b) crossover, c) mutation, d) natural selection, and e) reproduction. Individuals, which are solution candidates, are initially generated at random. Then, steps b, c, d, and e are repeatedly implemented until the termination condition is fulfilled. Each individual has a fitness value to the environment. The environment corresponds to the problem space and the fitness value corresponds to the evaluation value of objective function. Each individual has two aspects: Gene Type (GTYPE) expressing the chromosome or DNA and Phenomenon Type (PTYPE) expressing the solution. GA operations are applied to GTYPE and generate new children from parents (individuals) by effective searches in the problem space, and extend the search space by mutation to enhance the possibility of individuals other than the neighbor of the solution.

GA operations that generate useful children from their parents are performed by crossover operations of chromosomes or genes (GTYPE) without using special knowledge and intelligence. This characteristic is considered as one of the reasons of the successful applications of GA.

\subsection{Application of MOGA to Restoration Scheduling}

Table 16 presents the parameters of MOGA used here. Fig. 22 present the results obtained by MOGA. Table 17 shows the evaluation values of each solution. Then, the efficiency of MOGA is expressed as follows; for example, comparing solution $\mathrm{C}$ with 
Table 16. Parameters of MOGA

\begin{tabular}{cccc}
\hline Population Probability of crossover Probability of mutation & Generation \\
\hline 1000 & 0.6 & 0.005 & 1000 \\
\hline
\end{tabular}

Table 17. Evaluation values of each solution

\begin{tabular}{c|ccc}
\hline Solution & Restoring days & LCC & Safety level \\
\hline A & 14.234 & 241343 & 61.224 \\
B & 15.069 & 242300 & 62.123 \\
C & 16.309 & 254316 & 63.496 \\
D & 17.421 & 260416 & 63.756 \\
E & 17.565 & 265017 & 74.116 \\
F & 17.576 & 264866 & 80.011 \\
G & 17.546 & 284954 & 80.023 \\
H & 17.779 & 289676 & 80.229 \\
I & 17.898 & 292191 & 82.054 \\
J & 18.325 & 291942 & 82.234 \\
K & 18.649 & 301471 & 82.268 \\
L & 18.623 & 303837 & 82.302 \\
\hline
\end{tabular}

solution D in safety level, there is no significant difference between the two solutions. However, in restoring days and LCC, solution D is worse than solution C. On the other hand, comparing solution $\mathrm{E}$ with solution $\mathrm{F}$, there is no significant difference in restoring days between the two solutions. However, solution $\mathrm{F}$ is better than solution $\mathrm{E}$ in LCC. Moreover, in safety level, solution F is substantially better than solution E. In Table 17 comparing solution E with solution $\mathrm{G}$, there is no significant difference in restoring days between the two solutions. However, in safety level and LCC, there are significant differences between the two solutions.

In Fig. 23, the vertical axis represents LCC, whereas the horizontal axis represents restoring days. Fig. 24 presents the relation between restoring days and safety level. In Figs.23 and 24 since restoring days and the other two objective functions have a rather perfect positive linear correlation, it can be said that the other two can have a positive effect if restoring days can be increased. Fig. 25 presents the relation between LCC and safety level. In Figs. 24 and 25 it should be noted that it can be said that the other two objective function can have a positive effect when there is no significant difference in safety level.

Figs. 26 to 29 show the detailed restoration schedule associated with the solution $\mathrm{K}$ shown in Fig. 22. In Figs. 26 to 29, compared to the number of work to repair the roads, 


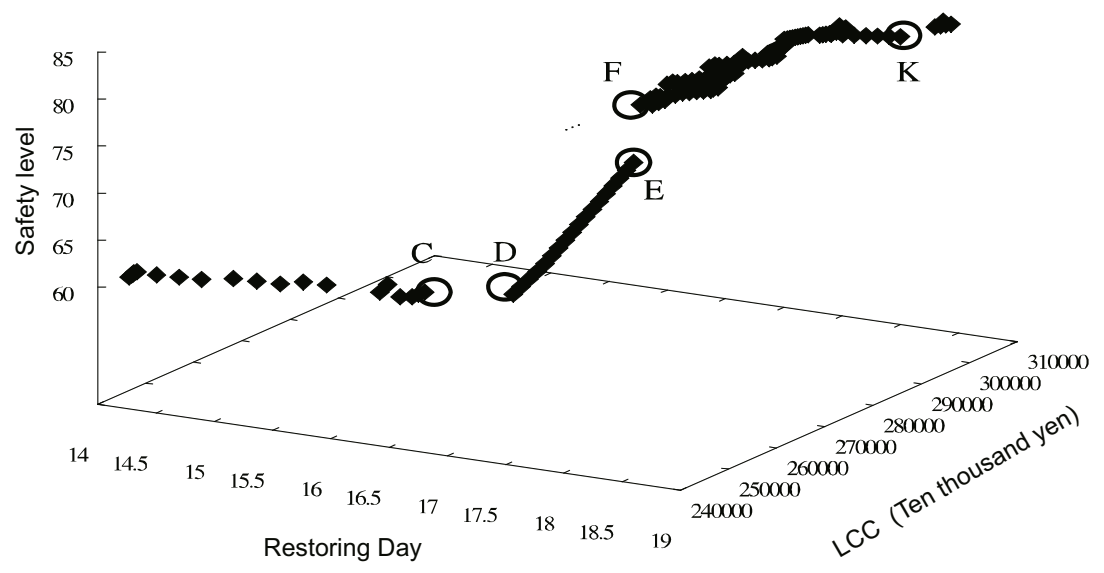

Fig. 22. Pareto solutions obtained by MOGA

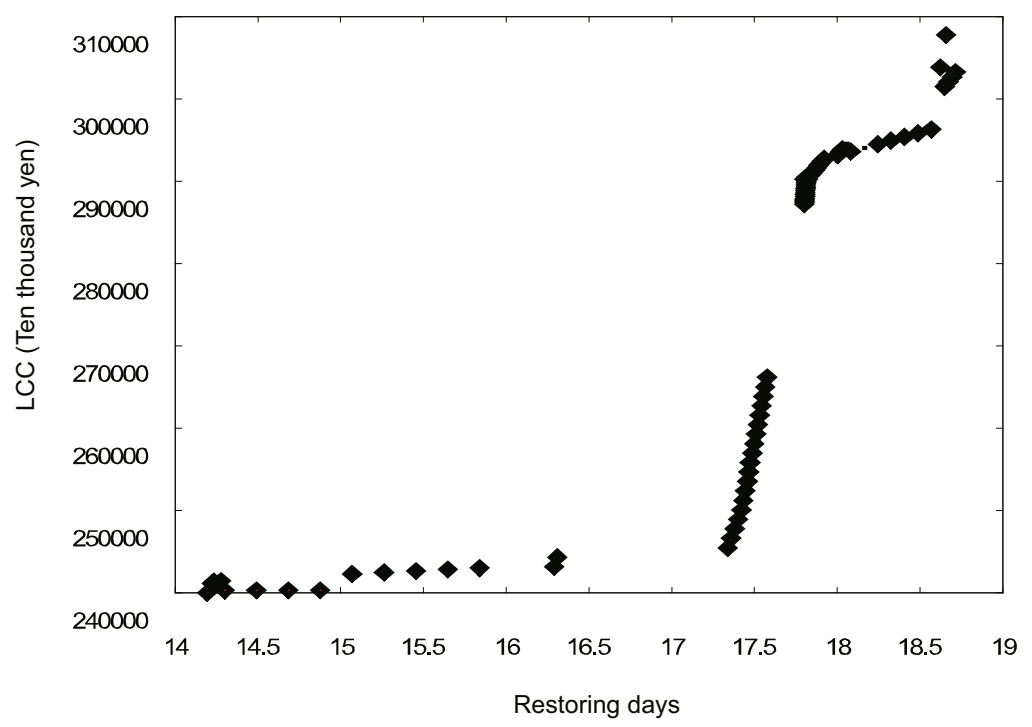

Fig. 23. Relation between restoring days and LCC

there are many works to reinforce the roads and to rebuild the roads, which can increase safety level, in some important links. As will be appreciated from Table 17 comparing solution $\mathrm{K}$ with the other solutions, solution $\mathrm{K}$ is worse than the other solutions in restoring days. However, solution $\mathrm{K}$ is better than the other solutions in safety level. 


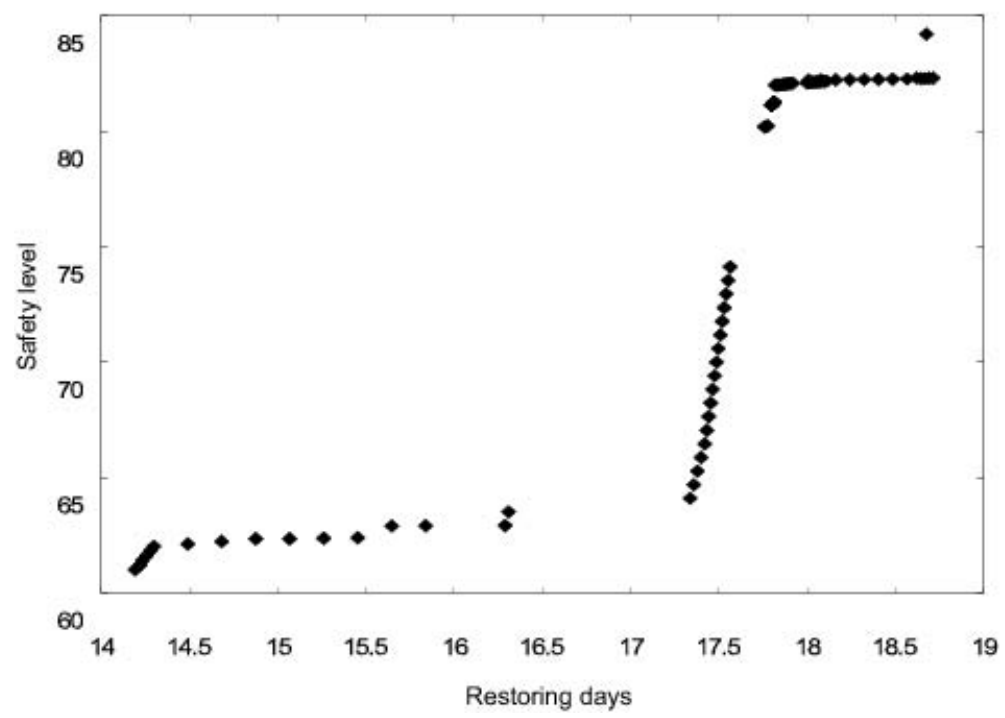

Fig. 24. Relation between restoring days and safety level

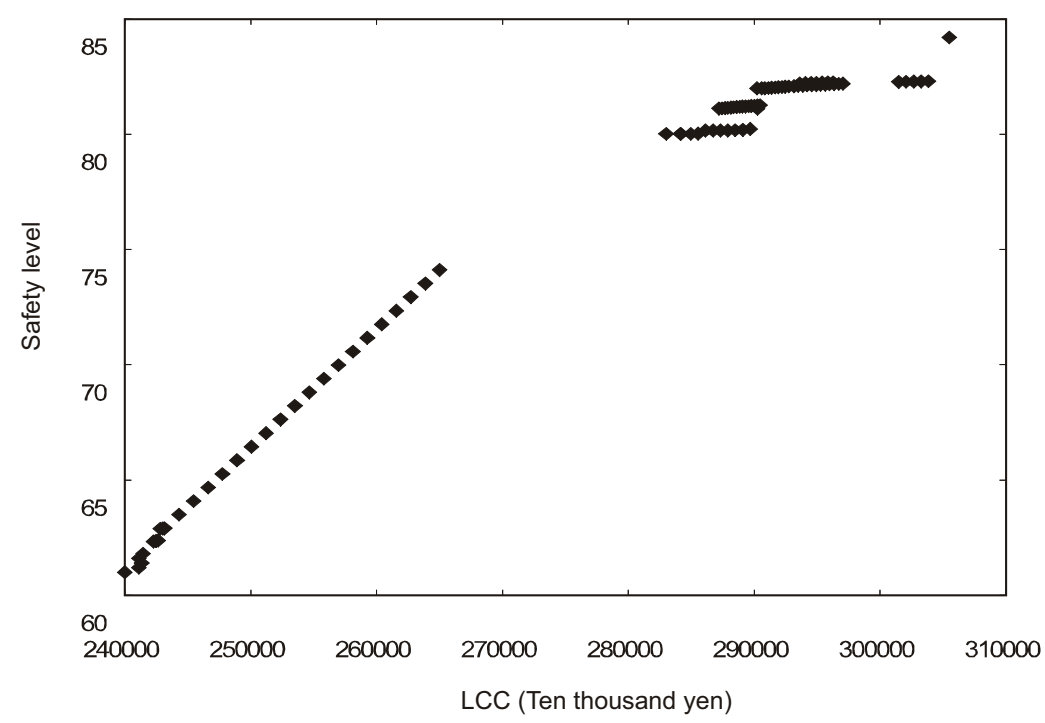

Fig. 25. Relation between LCC and safety level 


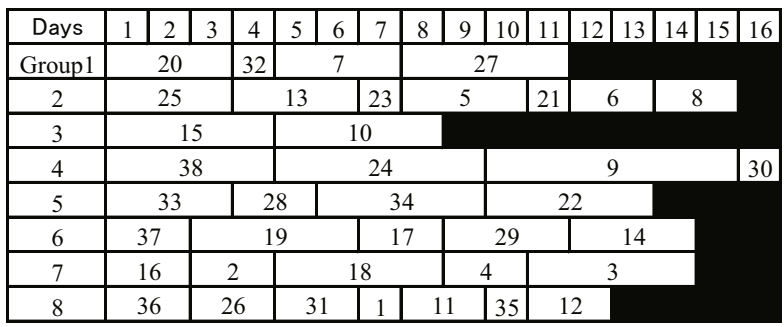

Fig. 26. Schedule of work to clear the interrupted things

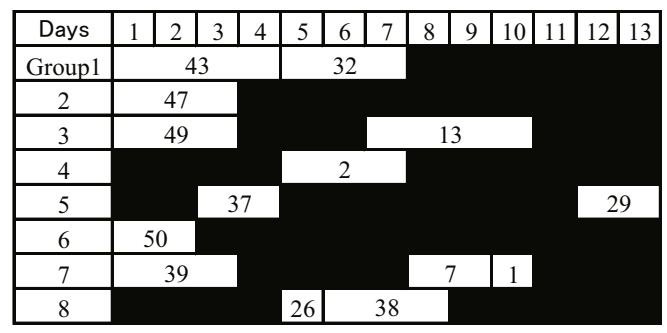

Fig. 27. Schedule of work to repair the roads

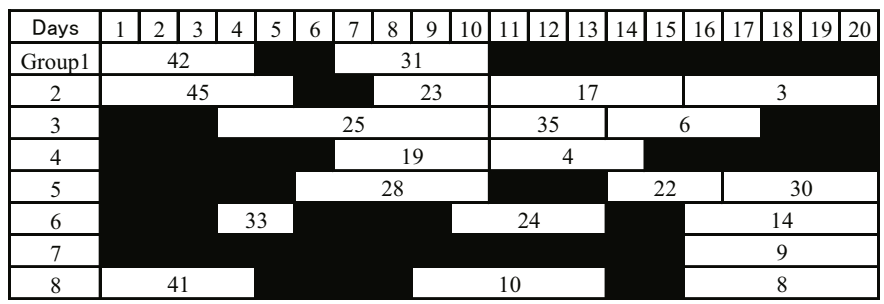

Fig. 28. Schedule of work to reinforce the roads

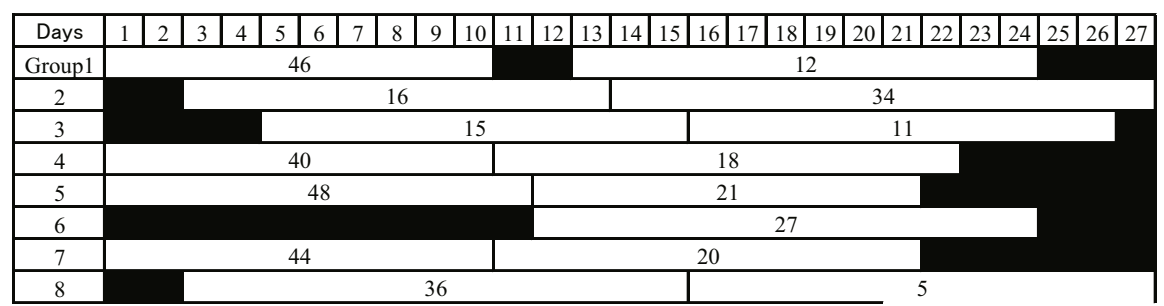

Fig. 29. Schedule of work to rebuild the roads 
From the above results, it is confirmed that various kinds of solutions can be obtained by the proposed method. Namely, when selecting a practical restoration schedule, the proposed method enables to compare feasible optional solutions obtained under various conditions.

\section{Optimal Maintenance Planning of Bridge Structures Using MOGA}

It has been widely recognized that maintenance work is important, because the number of existing bridges requiring repair or replacement increases in the future. In order to establish a rational maintenance program, it is necessary to develop a cost-effective decision-support system that can provide us with a practical and economical plan. Although low-cost maintenance plans are desirable for bridge owner, it is necessary to consider various constraints when choosing an appropriate actual maintenance program. For example, the minimization of maintenance cost requires to prescribe the target safety level and the expected service life time. The predetermination of requirements may loose the variety of possible maintenance plans. Namely, it may be possible to find out a better solution that can largely extend the service life if the safety level can be sensitively decreased even with the same maintenance cost.

It is desirable to discover many alternative maintenance plans with different characteristics. Although a single-objective optimization can provide various solutions by changing the constraints, it requires enormous computation time. When selecting a practical maintenance plan, it is useful to compare feasible solutions obtained under the various conditions. This process is inevitable and effective for the accountability by the disclosure of information. Then, an attempt was made to develop a decision support system for the bridge maintenance that can provide us with several alternative plans by applying Multi-Objective Genetic Algorithm (MOGA). However, it is not easy for the decision maker to choose an appropriate solution from many Pareto solutions. In order to help the decision maker, a 3D graphical system was developed using JAVA techniques. It is important to find out the appropriate repair methods and the branching points of cost effectiveness. Several numerical examples are presented to demonstrate the applicability and efficiency of the present system.

\subsection{Concrete Bridge Model}

A group of ten concrete highway bridges are considered. The locations of all these bridges along the coast of Japan are indicated in Fig. 30. Maintenance management planning for ten consecutive piers and floor slabs (composite structure of steel girders and reinforced concrete (RC) slabs) is considered. Each bridge has the same structure and is composed of six main structural components: upper part of pier, lower part of pier, shoe, girder, bearing section of floor slab, and central section of floor slab (Fig.31). In this study, an attempt was made to develop a new searching method for optimization problem. Environmental conditions can significantly affect the degree of deterioration 
of the structures and may vary from location to location according to geographical characteristics such as wind direction, amount of splash, etc. To take the environmental conditions into account, the deterioration type and year from completion of each bridge are summarized in Table 18

Table 18. Years from completion and type of deterioration caused by environmental conditions

\begin{tabular}{c|c|c}
\hline Bridge number & Years from completion & Deterioration type \\
\hline B01 & 2 & neutralization of concrete \\
B02 & 2 & neutralization of concrete \\
B03 & 0 & chloride attack (slight) \\
B04 & 0 & chloride attack (medium) \\
B05 & 0 & chloride attack (severe) \\
B06 & 0 & chloride attack (medium) \\
B07 & 0 & chloride attack (severe) \\
B08 & 1 & chloride attack (medium) \\
B09 & 1 & chloride attack (slight) \\
B10 & 1 & chloride attack (slight) \\
\hline
\end{tabular}

Environmental corrosion due to neutralization of concrete, chloride attack, frost damage, chemical corrosion, or alkali-aggregate reaction are considered as major deteriorations. The structural performance of each bridge component $i$ is evaluated by the associated safety level (also called durability level) $P_{i}$ which is defined as the ratio of current

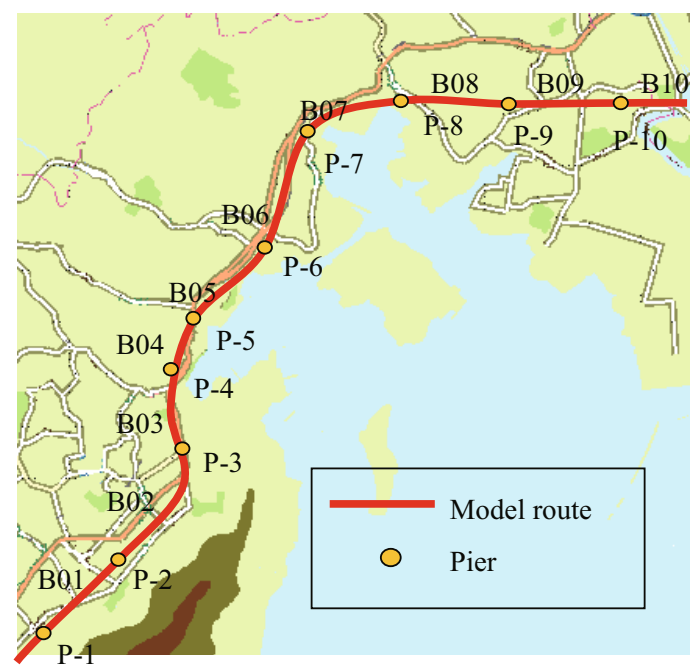

Fig. 30. Location of ten bridges in Japan 


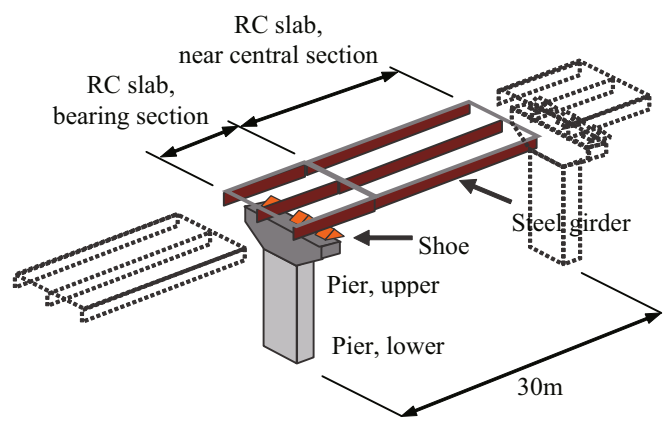

Fig. 31. Main components of a bridge

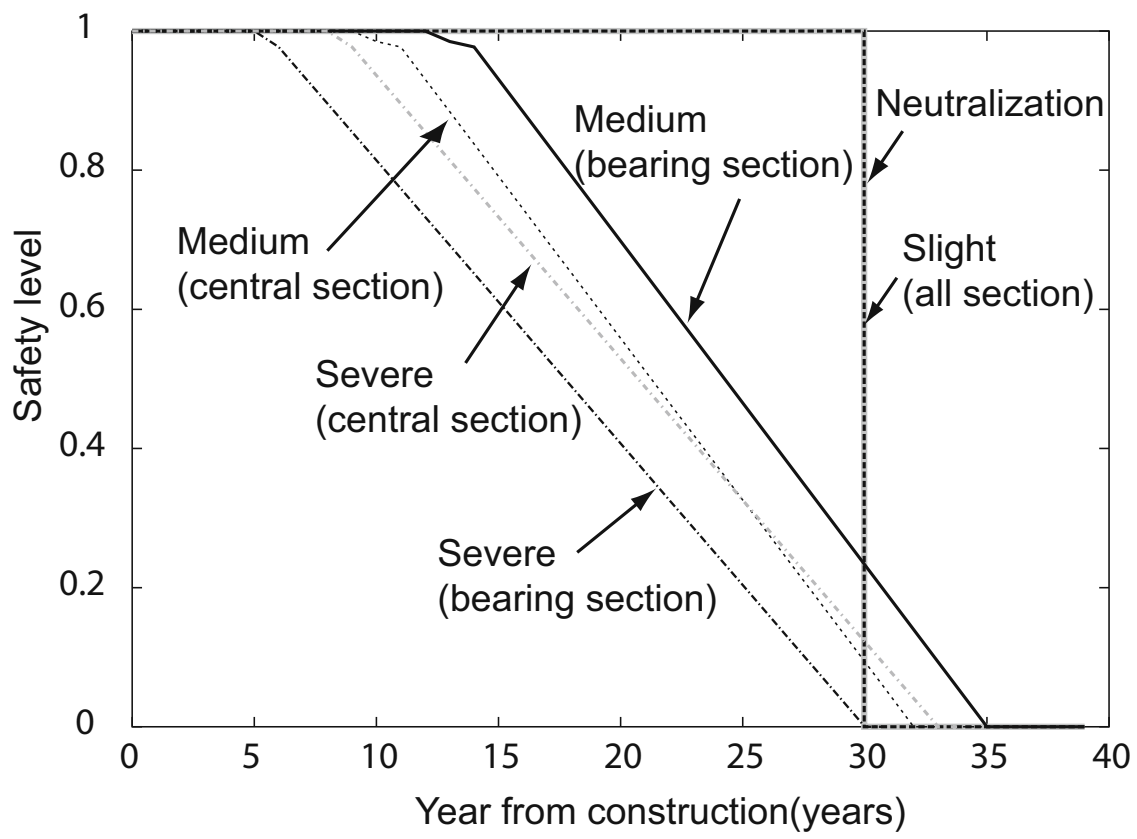

Fig. 32. Typical performance of RC slabs

safety level to initial safety level. Deterioration of a bridge due to corrosion depends on the concrete cover of its components and environmental conditions, among other factors. For each component, the major degradation mechanism and its rate of deterioration are assumed corresponding to associated environmental conditions. Figs. 32, 33. 


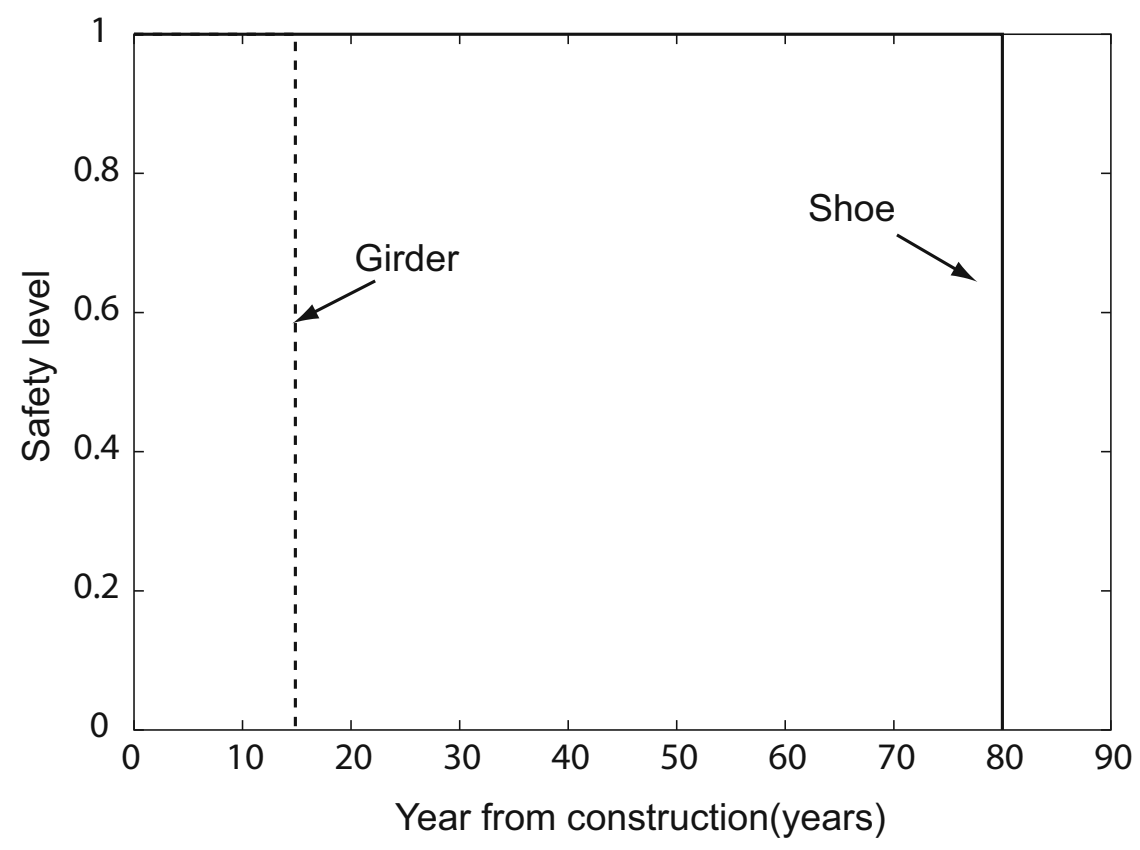

Fig. 33. Typical performance of shoes and girders

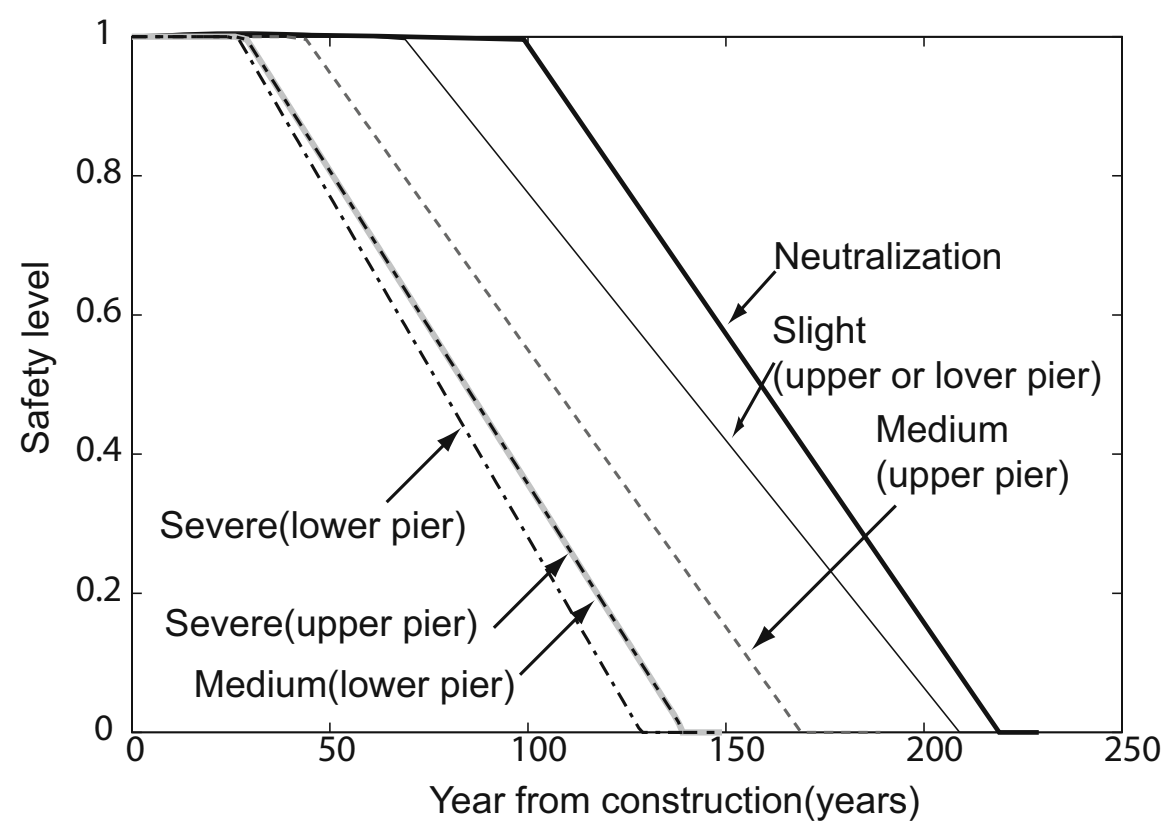

Fig. 34. Typical performance of piers 
and 34 show the decreasing patterns of safety levels for RC slabs, shoes and girders, and piers, respectively. Average values are employed here as representative values for each level of chloride attack because the deteriorating rates can vary even in the same environment. The decrease of RC slab performance is assumed to depend on corrosion. Hence, the safety level depends on the remaining cross-section of reinforcement bars. For shoe and girder, the major deterioration mechanism is considered to be fatigue due to repeated loadings. The decrease in performances occurs as the rubber bearing of shoe or paint coating of girder deteriorates. For pier, the major mechanism for deterioration is assumed to be only corrosion. Thus the reduced performance of pier is expressed by the remaining section of reinforcement bars. The development of reinforcement corrosion is determined in accordance with Standard Specification for Design and Construction of Concrete in Japan.

\subsection{Maintenance Methods}

In order to prevent deterioration in structural performance, several options such as repair, restoring, and reconstruction are considered. Their applicability and effects on each component are shown in Table 19 . Since the effects may differ even under the same conditions, average results are adopted here. Maintenance methods applicable to RC slab may vary according to the environmental conditions and are determined considering several assumptions.

Table 19. Effects of repair, restoring, and reconstruction

\begin{tabular}{c|c|c}
$\begin{array}{c}\text { Structural } \\
\text { component }\end{array}$ & Maintenance type & Average effect \\
\hline \multirow{4}{*}{ Pier or Slab } & $\begin{array}{c}\text { Surface painting } \\
\text { Surface covering }\end{array}$ & $\begin{array}{c}\text { Delays } P_{i} \text { decrease for 7 years } \\
\text { Delays } P_{i} \text { decrease for 10 years }\end{array}$ \\
\cline { 2 - 3 } & Section restoring & $\begin{array}{c}\text { Restores } P_{i} \text { to } 1.0 \text {, and then allows it to deteriorate } \\
\text { with the same slope as the initial deterioration curve }\end{array}$ \\
\cline { 2 - 3 } & $\begin{array}{c}\text { Desalting } \\
\text { (Re-alkalization) }\end{array}$ & $\begin{array}{c}P_{i} \text { deteriorates with the same slope } \\
\text { as the initial deterioration curve }\end{array}$ \\
\cline { 2 - 3 } & Cathodic protection & Delays $P_{i}$ decrease for 40 years \\
\cline { 2 - 3 } & $\begin{array}{c}\text { Section restoring with } \\
\text { surface covering }\end{array}$ & $\begin{array}{c}\text { Restores } P_{i} \text { to } 1.0, \text { delays } P_{i} \text { decrease for 10 years, } \\
\text { and then } P_{i} \text { deteriorates with the same slope } \\
\text { as the initial deterioration curve }\end{array}$ \\
\hline \multirow{2}{*}{ Girder } & Painting & $\begin{array}{c}\text { Maintains initial performance } \\
\text { until the end of the specified lifetime }\end{array}$ \\
\hline \multirow{2}{*}{ Shoe } & Replacement of bearing & $\begin{array}{c}\text { Maintains initial performance } \\
\text { until the end of the specified lifetime }\end{array}$ \\
\hline \multirow{2}{*}{ Slab } & Recasting & $\begin{array}{c}\text { Maintains initial performance } \\
\text { until the end of the specified lifetime }\end{array}$ \\
\hline & Reconstruction & $\begin{array}{r}\text { Restore } P_{i} \text { to } 1.0, \text { delays } P_{i} \text { decrease for } 10 \text { years, } \\
\text { and then } P_{i} \text { deteriorates with the same slope } \\
\text { as the initial deterioration curve }\end{array}$ \\
\hline
\end{tabular}




\subsection{LCC}

LCC is defined as the total maintenance cost for the entire bridge group during its life. This is obtained by the summation of the annual maintenance costs through the service life of the bridges. The future costs are discounted to their present values. Other costs, such as indirect construction costs, general costs, administrative costs, etc., are calculated in accordance with Cost Estimation Standards for Civil Construction. The direct construction costs consist of material and labor costs and the cost of scaffold. The breakdown of the material and labor costs and the cost of the scaffold are shown in Tables 20 and 21. The construction costs are based upon the market prices.

Table 20. Material and labor costs

\begin{tabular}{|c|c|c|c|c|c|c|}
\hline $\begin{array}{c}\text { Maintenance } \\
\text { action }\end{array}$ & $\begin{array}{c}\text { Upper pier } \\
\left(\text { yen } / m^{2}\right)\end{array}$ & \begin{tabular}{|c} 
Lower pier \\
$\left(\right.$ yen $\left./ m^{2}\right)$
\end{tabular} & $\begin{array}{c}\text { Shoe } \\
\text { (yen/part) }\end{array}$ & $\begin{array}{c}\text { Girder } \\
\left(\text { yen } / m^{2}\right)\end{array}$ & $\begin{array}{c}\text { Slab } \\
\text {-central } \\
\text { section- } \\
\left(\text { yen } / m^{2}\right)\end{array}$ & $\begin{array}{c}\text { Slab } \\
\text {-bearing } \\
\text { section- } \\
\left(\text { yen } / m^{2}\right)\end{array}$ \\
\hline Surface painting & 780,000 & $1,920,000$ & - & - & $1,640,000$ & $3,280,000$ \\
\hline Surface covering & $2,730,000$ & $6,720,000$ & - & - & $4,100,000$ & $8,200,000$ \\
\hline $\begin{array}{l}\text { Section restoring } \\
\text { Desalting }\end{array}$ & $20,670,000$ & $50,880,000$ & - & - & $22,140,000$ & $44,280,000$ \\
\hline (Re-alkalization) & $3,510,000$ & $8,640,000$ & - & - & $7,380,000$ & $14,760,000$ \\
\hline $\begin{array}{l}\text { Cathodic } \\
\text { protection }\end{array}$ & $3,900,000$ & $9,600,000$ & - & - & $8,200,000$ & $16,400,000$ \\
\hline $\begin{array}{l}\text { Section restoring } \\
\text { with }\end{array}$ & & & & & & \\
\hline $\begin{array}{l}\text { surface covering } \\
\text { Reconstruction }\end{array}$ & $\begin{array}{c}22,620,000 \\
-\end{array}$ & $\begin{array}{c}55,680,000 \\
-\end{array}$ & $\begin{array}{c}- \\
4,200,000\end{array}$ & $\begin{array}{c}- \\
5,400,000\end{array}$ & $\begin{array}{l}26,240,000 \\
12,300,000\end{array}$ & $\begin{array}{l}52,480,000 \\
24,600,000\end{array}$ \\
\hline
\end{tabular}

Table 21. Scaffold costs

\begin{tabular}{c|c|c|c|c|c}
\hline $\begin{array}{c}\text { Upper pier } \\
\left(\text { yen } / \mathrm{m}^{2}\right)\end{array}$ & $\begin{array}{c}\text { Lower pier } \\
\left(\text { yen } / \mathrm{m}^{2}\right)\end{array}$ & $\begin{array}{c}\text { Shoe } \\
(\text { yen/part })\end{array}$ & $\begin{array}{c}\text { Girder } \\
\left(\text { yen } / \mathrm{m}^{2}\right)\end{array}$ & $\begin{array}{c}\text { Slab } \\
\text {-central section- } \\
\left(\text { yen } / \mathrm{m}^{2}\right)\end{array}$ & $\begin{array}{c}\text { Slab } \\
\text {-bearing section- } \\
\left(\text { yen } / \mathrm{m}^{2}\right)\end{array}$ \\
\hline 360,000 & 190,000 & 360,000 & $4,830,000$ & 690,000 & 510,000 \\
\hline
\end{tabular}

\subsection{Application of MOGA to Maintenance Planning}

It is desirable to determine an appropriate life-cycle maintenance plan by comparing several solutions for various conditions. A new decision support system is described here from the viewpoint of multi-objective optimization, in order to provide various solutions needed for the decision-making.

LCC, safety level and service life are used as objective functions. LCC is minimized, safety level is maximized, and service life is maximized. There are trade-off relations 
among the three objective functions. For example, LCC increases when service life is extended, and safety level and service life decrease due to the reduction of LCC. Then, multi-objective optimization can provide a set of Pareto solutions that cannot improve an objective function without making other objective functions worse.

In the present system, DNA structure is constituted as shown in Fig. 35, in which DNA of each individual consists of three parts such as repair method, interval of repair, and shared service life (Fig. 36). In this figure, service life is calculated as the sum of repairing years and their interval years. In Fig. 36, service life is obtained as 67 years which is expressed as the sum of 30 years and 37 years. The repair part and the interval part have the same length. Gene of repair part has ID number of repair method.

The interval part has enough length to consider service life. In this system, ID 1 means surface painting, ID 2 surface coating, ID 3 section restoring, ID 4 desalting (realkalization) or cathodic protection, and ID 5 section restoring with surface covering. DNA of service life part has a binary expression with six bits and its value is changed

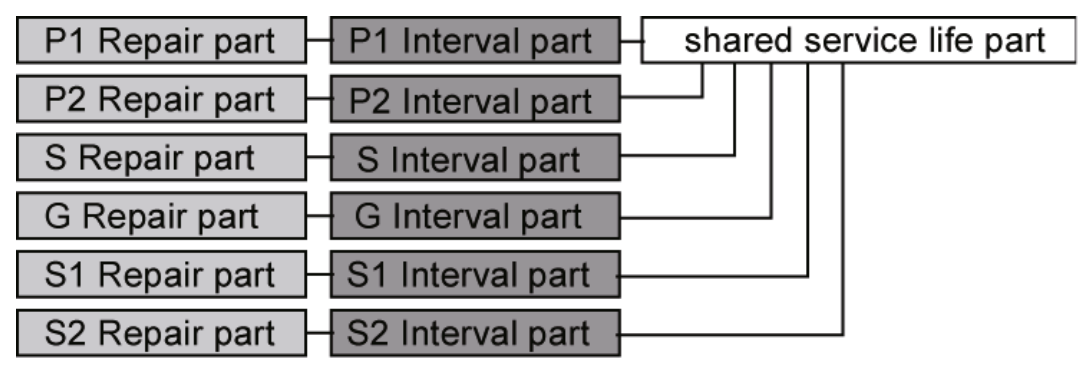

Fig. 35. Structure of DNA

GTYPE

Repair method part Interval of repair Service life

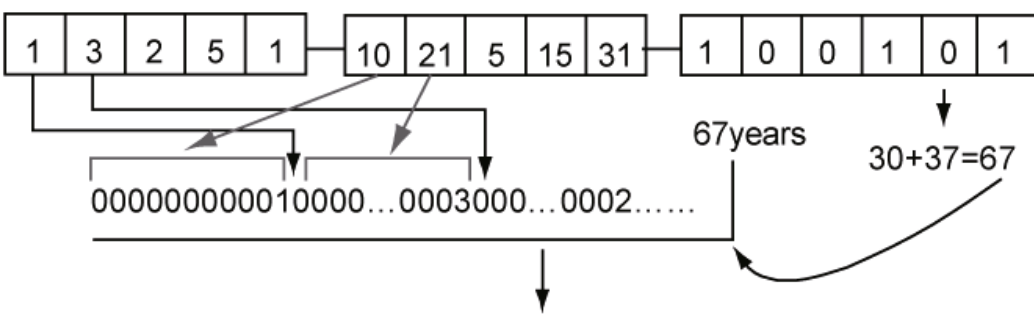

$000 \ldots 0001000 \ldots . .00300 \ldots 0200 \ldots 0005000 \ldots 00$

PTYPE: Maintenance schedule

67years plan

Fig. 36. Coding rule 
to decimal number. For mutation, the system shown in Fig. 36 is used. Then, objective functions are defined as follows:

$$
\text { Objective function 1: } \quad C_{\text {total }}=\sum L C C_{i} \rightarrow \min
$$

where $L C C_{i}$ is $L C C$ for bridge $i$.

$$
\text { Objective function 2: } \quad Y_{\text {total }}=\sum Y_{i} \rightarrow \max
$$

subject to $Y_{i}>Y_{\text {required }}$, where $Y_{i}$ is service life of bridge $i, Y_{\text {required }}$ is required service life.

$$
\text { Objective function 3: } \quad P_{\text {total }}=\sum P_{i} \rightarrow \max
$$

subject to $P_{i}>P_{\text {target }}$, where $P_{\text {target }}$ is target safety level.

The above objective functions have trade-off relations to each other. Namely, the maximization of safety level or maximization of service life cannot be realized without increasing LCC. On the other hand, the minimization of LCC can be possible only if the service life and/or the safety level decreases.

\subsection{Three-Dimensional Graphical Systems}

In order to find out several useful solutions from the set of Pareto solutions, a 3D graphical system was developed. The system aims to help the decision maker to select several solutions that satisfy some requirements through checking their constraint conditions by using JAVA3D. The system consists of three subsystems: 1) 3D representation, 2) general representation, and 3) graphical representation. Each representation is implemented using JAVA language.

The 3D representation system is the most important among the three subsystems. This system can select several candidates from the set of Pareto solutions by checking various requirements and express them in 3D graphics. In this study, both MOGA system and the 3D graphical system are written in JAVA so that the rendering of 3D graphs can be implemented in real time. Namely, the user can move the 3D graphs freely. It is very easy to move them by using a mouse. Any graph can be viewed from any direction by using the operations of extension, shrinkage, translation, and rotation. The 3D representation system can mainly implement the three actions: 1) emphasize the evaluation function, 2) emphasize a point, and 3) extract a range.

The general representation system can list the solutions obtained by the 3D representation system. The solutions can be arranged in the order of evaluation values. The solutions are listed up, corresponding to the range defined by MOGA system. While the $3 \mathrm{D}$ representation system is useful to grasp the relations and tendencies of solutions, the general representation system is useful to show the characteristics of each solution.

The graphical representation system can provide us with the detail of repair methods calculated by MOGA. The system can play a role in checking the appropriateness of the obtained repair methods and in finding out the tendency or pattern of repair program. 
Observing and comparing the patterns obtained, it is possible to discover the branching points of short, medium and long term repair plans.

\subsection{Application Example}

Fig. 37 shows the Pareto solutions calculated by MOGA system. This graph is given in the conventional way of representation.

Fig. 38 shows the representation of the same graph by the proposed 3D representation system. Fig. 39 presents the same graph that is rotated and shrunken. As seen form Fig. 39, it is possible for the user to check the Pareto solutions from any desired direction by using the proposed representation system based on JAVA3D.

For example, it is possible to find out a gap among the solutions, which may be caused by the cost reduction by the common usage of scaffold. Apparently, it is possible to obtain more useful information by using the $3 \mathrm{D}$ representation instead of the usual 2D representation. Comparing the long term repair plans and short term repair plans, it is made clear that the long term plan is superior in monetary term to the plan with the repetition of short term repair (Table 22). The branching point between the short term plan and long term plan can be found out. Moreover, it is also possible to obtain the solutions for the cases in which the safety of the structure is emphasized and the LCC is emphasized, respectively. This means that the proposed system can provide the user with an appropriate solution for any case.

By considering LCC, safety level, and service life as objective functions, it is possible to obtain the relationships among these three performance indicators and provide

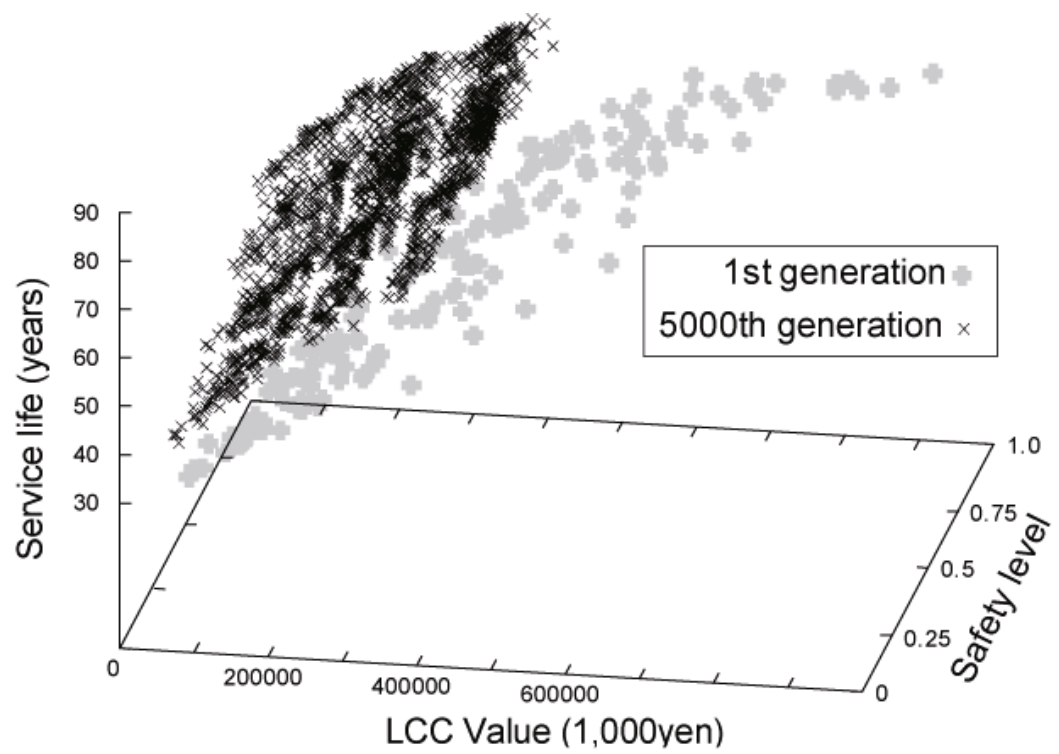

Fig. 37. Pareto solutions obtained by MOGA 


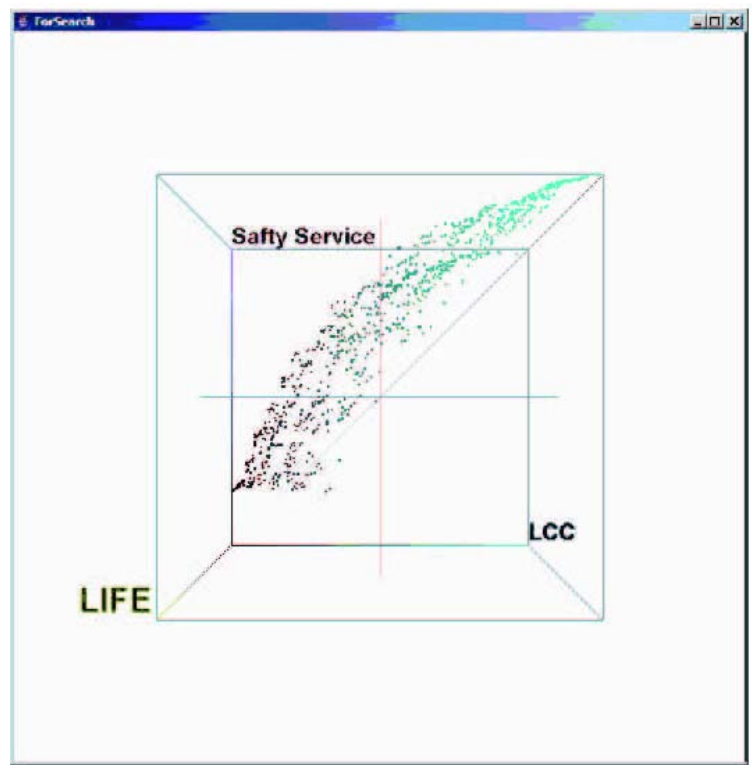

Fig. 38. JAVA 3D Application 1

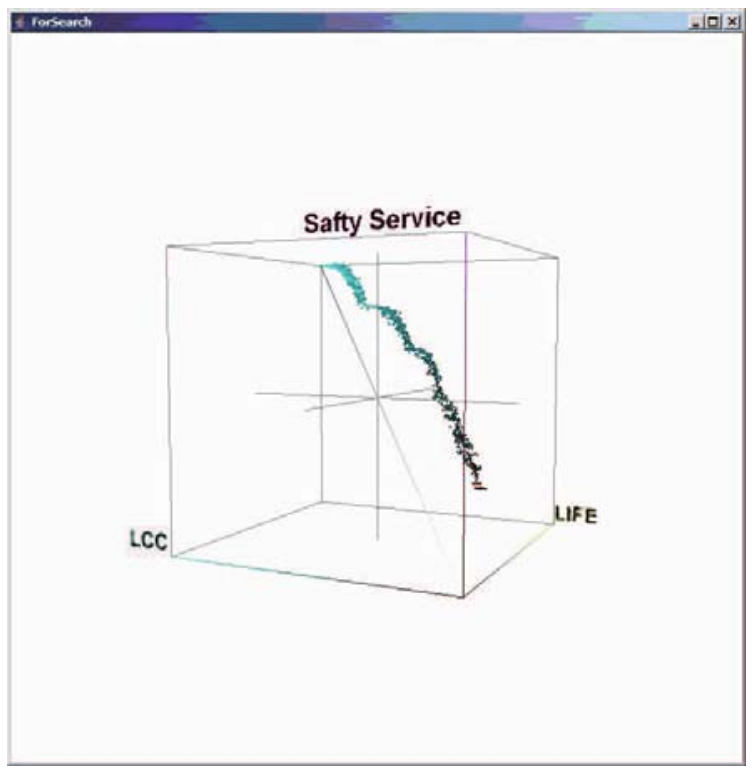

Fig. 39. JAVA 3D Application 2 
Table 22. Maintenance terms

\begin{tabular}{c|ccc}
\hline Maintenance term & LCC & \multicolumn{2}{c}{ Safety level } \\
\hline long term & 359501 & 5.18887 & 84 \\
middle term & 308605 & 5.18132 & 66 \\
short term & 255104 & 5.18154 & 40 \\
\hline
\end{tabular}

bridge maintenance management engineers with various maintenance plans with appropriate allocations of resources. Since the optimal maintenance problem is a very complex combinatorial problem, it is difficult to obtain reasonable solutions by the current optimization techniques. Although GA is applicable to solve multi-objective problems, it is difficult to apply it to large and very complex bridge maintenance problems. By introducing the technique of Non-Dominated Sorting GA-2 (NSGA2), it is possible to obtain efficient near-optimal solutions for the maintenance planning of a group of bridge structures. However, it is not easy for the decision maker to choose an appropriate solution from many Pareto solutions. In order to help the decision maker, a 3D graphical system is developed using JAVA techniques. It is important to find the appropriate repair methods and the branching points of cost effectiveness.

\section{Conclusions}

In this paper, several practical optimization methods including GA were introduced, which are based on "evolutionary computing" or "soft computing". Several application examples in structural engineering are presented to discuss the efficiency and applicability of the methods described here. Through the numerical computations, the following conclusions were derived:

1. The optimization problems in real life are very difficult to solve, because they have objective functions and constraint conditions which have uncertainty and vagueness.

2. The evolutionary computing including GA is useful in solving real life problems, because of their superior ability such as understandable thinking way, high searching performance, easiness of programming, and robustness to peculiar characteristics of problems.

3. The structural vibration control system presented in this paper has an advantage that it can adapt to the change of structural systems and environments. Through the model and numerical experiments, it was validated that the systems can follow the change of vibration characteristics of structure. Using the descent method for the learning in fuzzy reasoning, quick and right adaptation can be achieved.

4. A decision support system for the aesthetic design of bridge handrails can be applied for practical use. In order to obtain several satisfactory design alternatives, the immune algorithm was applied to the optimization procedure and the neural network was used for the learning of the necessary knowledge. The effectiveness of the system was confirmed through numerical calculations. 
5. The optimal restoration scheduling was formulated as a multi-objective optimization problem. By considering restoring days, LCC and performance level as objective functions, it is possible to obtain the relationships among these three performance indicators and to compare feasible optional solutions obtained under various conditions.

6. An optimal maintenance planning problem was also formulated as a multi-objective optimization. Furthermore, a 3D graphical representation system was introduced to find out several useful solutions from the set of Pareto solutions obtained by the optimal maintenance planning system using Multi-Objective Genetic Algorithm (MOGA).

7. By comparing the method with the current methods, it was proven that the present method can reduce the computation time, improve the convergence of searching procedure, regardless of vague or uncertain objective functions and constraint functions.

\section{References}

1. Soong, T.T.: Active Structural Control: Theory and Practice. Addison-Wesley, Reading (1990)

2. Furuhashi, T., Hayashi, I.: Fuzzy Neural Network. Asakura Publishing (1996) (in Japanese)

3. Uchikawa, Y.: Fuzzy Neural System. Nikkan Kogyo (1995) (in Japanese)

4. Dayhoff, J.E.: Neural Network Architectures: An Introduction. Van Nostrand Reinhold (1990)

5. Wang, L.X., Mendel, J.M.: Back-propagation fuzzy systems as nonlinear dynamic system identifiers. In: Proceedings of the IEEE International Congress on Fuzzy System (1992)

6. Furuta, H., et al.: Development of a decision support system for aesthetic design of existing and new girder bridges. Journal of Structural Engineering, JSCE 46A, 321-331 (2000) (in Japanese)

7. Mori, K., et al.: An immunity-based algorithm that offers diversity and its application to load allocation problems. Proceedings of Institute of Electrical Engineers of Japan, Part C 113(10), 872-878 (1993) (in Japanese)

8. Furuta, H., Nakatsu, K.: Optimal restoration scheduling for earthquake disaster by emergent computing. In: Proceedings of the IFIP WG 7.5 on Reliability and Optimization of Structural Systems, Banff, Alberta, Canada, November 2-5 (2003); Maes, M.A., Huyse, L. (eds.): Reliability and Optimization of Structural Systems, pp. 267-274. A.A. Balkema Publ., Leiden (2004)

9. Furuta, H., Nakatsu, K., Frangopol, D.M.: Optimal restoration scheduling for earthquake disaster using life-cycle cost. In: Proceedings of the Fourth International Workshop on LifeCycle Cost Analysis and Design of Civil Infrastructure Systems, Cocoa Beach, Florida, May 8-11 (2005); Nowak, A.S., Frangopol, D.M. (eds.): Advances in Life-Cycle Analysis and Design of Civil Infrastructure Systems, pp. 47-54. University of Nebraska (2005)

10. Furuta, H., Sugimoto, H.: Applications of Genetic Algorithm to Structural Engineering. Morikita Publishing, Tokyo (1997) (in Japanese)

11. Frangopol, D.M., Furuta, H. (eds.): Life-Cycle Cost Analysis and Design of Civil Infrastructure Systems. ASCE, Reston (2001)

12. Goldberg, D.E.: Genetic Algorithms in Search, Optimization and Machine Learning. Addison Wesley Publishing Company, Inc., Reading (1989) 
13. Furuta, H., Kameda, T., Fukuda, Y., Frangopol, D.M.: Life-Cycle Cost Analysis for Infrastructure Systems: Life Cycle Cost vs. Safety Level vs. Service Life. In: Proceedings of Joint International Workshops LCC03/IABMAS and fip/JCSS, EPFL, Lausanne, March 24-26 (2003) (keynote lecture); Frangopol, D.M., Brühwiler, E., Faber, M.H., Adey, B. (eds.): LifeCycle Performance of Deteriorating Structures: Assessment, Design and Management, pp. 19-25. ASCE, Reston (2004)

14. Liu, M., Frangopol, D.M.: Probabilistic maintenance prioritization for deteriorating bridges using a multi-objective genetic algorithm. In: Proceedings of the Ninth ASCE Joint Specialty Conference on Probabilistic Mechanics and Structural Reliability, Omnipress, Albuquerque, July 26-28. Hosted by Sandia National Laboratories, New Mexico (2004), 6 pages on CDROM

15. Liu, M., Frangopol, D.M.: Optimal bridge maintenance planning based on probabilistic performance prediction. Engineering Structures 26(7), 991-1002 (2004)

16. Furuta, H., Kameda, T., Nakahara, K., Takahashi, Y.: Genetic algorithm for optimal maintenance planning of bridge structures. In: Proc. of GECCO, Chicago, USA (2003)

17. Kitano, H. (ed.): Genetic Algorithm 3. Sangyo-tosho, Tokyo (1995) (in Japanese) 